San Jose State University

SJSU ScholarWorks

Master's Theses

Master's Theses and Graduate Research

Summer 2012

\title{
Assessment of Water Storage Trends and Distributions in the Mississippi River Basin as Simulated by IPCC Models and Compared to GRACE Satellite Data
}

Katherine Pitts

San Jose State University

Follow this and additional works at: https://scholarworks.sjsu.edu/etd_theses

\section{Recommended Citation}

Pitts, Katherine, "Assessment of Water Storage Trends and Distributions in the Mississippi River Basin as Simulated by IPCC Models and Compared to GRACE Satellite Data" (2012). Master's Theses. 4208. DOI: https://doi.org/10.31979/etd.7xfk-gsu7

https://scholarworks.sjsu.edu/etd_theses/4208

This Thesis is brought to you for free and open access by the Master's Theses and Graduate Research at SJSU ScholarWorks. It has been accepted for inclusion in Master's Theses by an authorized administrator of SJSU ScholarWorks. For more information, please contact scholarworks@sjsu.edu. 


\title{
ASSESSMENT OF WATER STORAGE TRENDS AND DISTRIBUTIONS IN THE MISSISSIPPI RIVER BASIN AS SIMULATED BY IPCC MODELS AND COMPARED TO GRACE SATELLITE DATA
}

\author{
A Thesis \\ Presented to \\ San José State University \\ In Partial Fulfillment \\ of the Requirements for the Degree \\ Master of Science
}

The Faculty of the Department of Meteorology and Climate Science

by

Katherine L. Pitts

August 2012 
(C) 2012

Katherine L. Pitts

ALL RIGHTS RESERVED 
The Designated Thesis Committee Approves the Thesis Titled

\title{
ASSESSMENT OF WATER STORAGE TRENDS AND DISTRIBUTIONS IN THE MISSISSIPPI RIVER BASIN AS SIMULATED BY IPCC MODELS AND COMPARED TO GRACE SATELLITE DATA
}

\author{
by \\ Katherine L. Pitts \\ APPROVED FOR THE DEPARTMENT OF METEOROLOGY \\ AND CLIMATE SCIENCE
}

SAN JOSÉ STATE UNIVERSITY

August 2012

Dr. Alison F. C. Bridger Department of Meteorology and Climate Science

Dr. Eugene C. Cordero Department of Meteorology and Climate Science

Dr. Frank Freedman Department of Meteorology and Climate Science

Dr. Cristina Milesi CSU Monterey Bay/NASA Ames Research Center 


\title{
ABSTRACT \\ ASSESSMENT OF WATER STORAGE TRENDS AND DISTRIBUTIONS IN THE MISSISSIPPI RIVER BASIN AS SIMULATED BY IPCC MODELS AND COMPARED TO GRACE SATELLITE DATA
}

\author{
by Katherine L. Pitts
}

Published work has shown that GRACE water storage estimates are consistent with water storage observations for many river basins. GRACE data can therefore serve as a proxy for water storage data. In this analysis, we compare estimates of total water storage (TWS) anomalies from the GRACE mission to soil moisture (SM) data from IPCC AR4 simulations for the Mississippi River Basin (MSRB). IPCC models do not carry a TWS variable for direct comparison. Therefore, we use the IPCC models' soil moisture content parameter to compare to the GRACE data, because TWS variability in the mid-latitudes is mostly due to SM variability. GRACE data are thus used to validate hydrological output from IPCC models, and trends are then examined to project future water storage for this river basin for the $21^{\text {st }}$ century.

Our analysis shows that the composited seasonally-varying TWS anomaly fields for the MSRB computed by IPCC models correlate well with the composite GRACE anomaly field over the period 2002-09, with most correlations greater than 0.9 . However, the IPCC model-simulated spatial variations of water storage vary considerably among the models. These differences are in contrast to the broadly similar precipitation and evaporation distributions among the models examined. Our validation efforts suggest that the land models from the IPCC AR4 models need to better capture regional variations in SM before they can be used for reliable projections of this variable. 


\section{ACKNOWLEDGEMENTS}

I would like to profusely thank my thesis advisor, Dr. Alison Bridger, for her guidance, patience, and generous amounts of constructive criticism given during the extent of this project. I am extremely grateful for all the time she has taken out of her always busy and chaotic schedule as department chair to help me succeed in my graduate school endeavors.

I would also like to thank the rest of my thesis committee - Dr. Eugene Cordero, Dr. Frank Freedman, and Dr. Cristina Milesi - for their support throughout the years. From taking Dr. Cordero's classes in climate change, climate modeling, and statistics, I was amply prepared to do the work required for this thesis, as well as for other research projects outside of school. From the many conversations with Dr. Freedman, and his sharing of knowledge of the land physics within models, I have been able to grasp the knowledge of a scientific field just outside the bounds of meteorology. And from Dr. Milesi's encouragement and timely responses to any problem big or small - not just through this thesis, but also as an advisor for other quick-paced and high-intensity research projects at NASA Ames Research Center - have I found the courage to tackle seemingly impossible hurdles, and push myself toward higher goals.

Finally, I acknowledge the modeling groups, the Program for Climate Model Diagnosis and Intercomparison (PCMDI) and the WCRP's Working Group on Coupled Modelling (WGCM) for their roles in making available the WCRP CMIP3 multi-model dataset. Support of this dataset is provided by the Office of Science, U.S. Department of Energy. 


\section{TABLE OF CONTENTS}

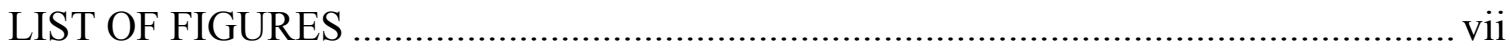

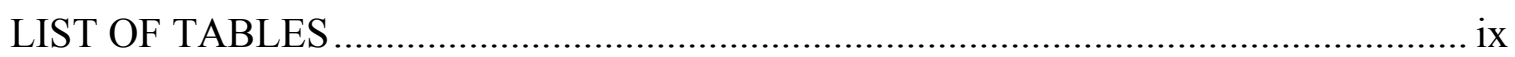

1. Introduction and literature review of GRACE satellite data and IPCC model data ....... 1

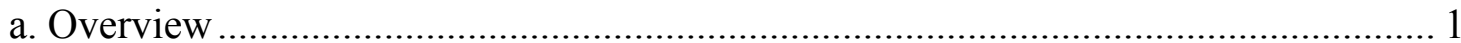

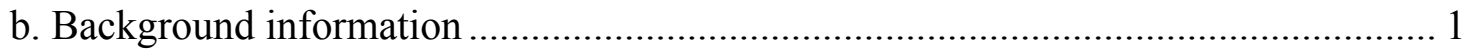

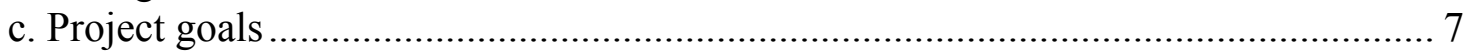

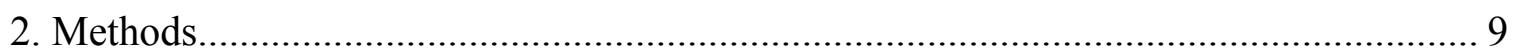

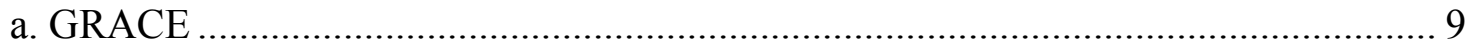

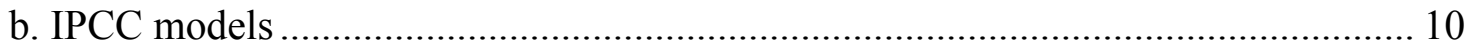

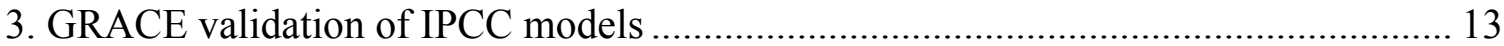

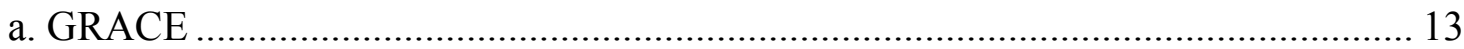

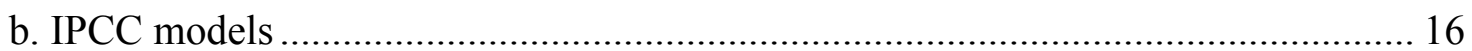

1) Annual cycle anomaly composite................................................................. 16

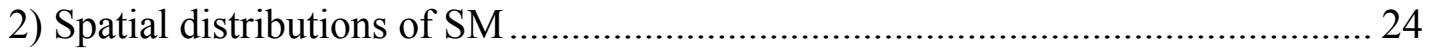

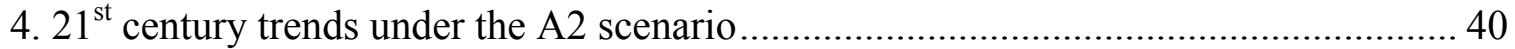

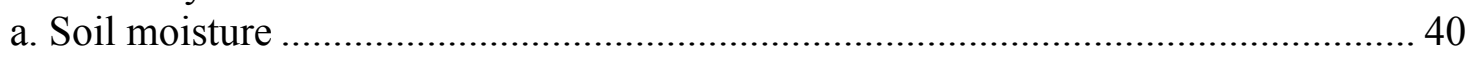

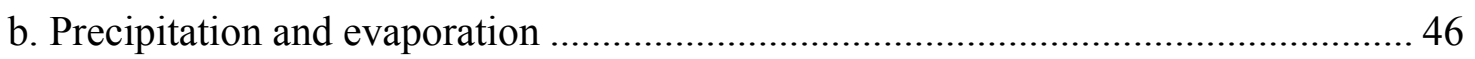

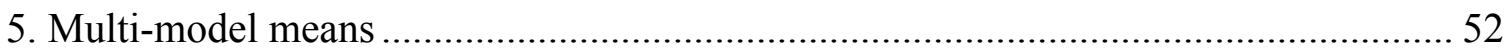

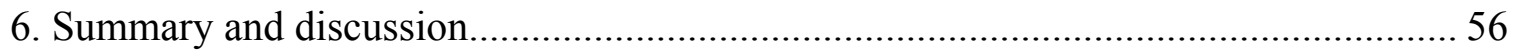

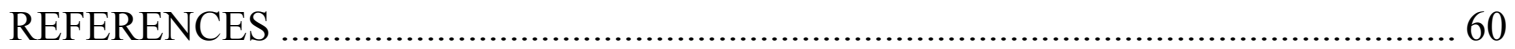




\section{LIST OF FIGURES}

Fig. 1. HadCM3 model grid points (red diamonds) encompassed within the MSRB

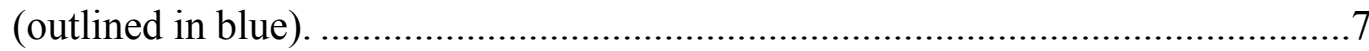

Fig. 2. Time series of GRACE monthly TWS anomaly data averaged across the MSRB with trend line.

Fig. 3. Annual cycles of GRACE-derived TWS anomaly for the MSRB for the period May 2002 to November 2009, with composite shown in the thick, black line.

Fig. 4. Annual cycle of model SM anomaly for each of the models analyzed in this study for the MSRB over the simulated period May 2002 to November 2009. Also shown is the corresponding GRACE TWS anomaly composite

Fig. 5. HadGEM1 annual SM anomaly composites for the time periods May 2002 to November 2009, May 2010 to November 2017, and May 2018 to November 2025. GRACE composite is overlaid in thick, black line.

Fig. 6. Spatial distribution of SM simulated by HadGEM1 (top) and MRI (bottom) models averaged over GRACE observational period. Scale is from 0 to $1400 \mathrm{~kg} \mathrm{~m}^{-2}$

Fig. 7. Same as Fig. 6 but extended to all models analyzed in this thesis. Models from top of first column: HadGEM1, MRI, GISS, IPSL, HadCM3, CCSM3, MIROC, INM CM3. Scale is from 0 to $1400 \mathrm{~kg} \mathrm{~m}^{-2}$.

Fig. 8. Top (a): NARR monthly SM averaged from 1979 to 2010. Bottom (b): NARR monthly SM averaged from 2002 to 2009. Scale is from 200 to $1200 \mathrm{~kg} \mathrm{~m}^{-2}$

Fig. 9. Spatial distribution of monthly P simulated by HadGEM1 (top) and MRI (bottom) models averaged over GRACE observational period. Scale is from 0 to $350 \mathrm{~mm}$.

Fig. 10. Same as Fig. 9 but extended to all models analyzed in this thesis. Models from top of first column: HadGEM1, MRI, GISS, IPSL, HadCM3, CCSM3, MIROC, INM CM3. Scale is from 0 to $350 \mathrm{~mm}$.

Fig. 11. Spatial distribution of monthly E simulated by HadGEM1 (top) and MRI (bottom) models averaged over GRACE obs period. Scale is from 0 to 350 $\mathrm{kg} \mathrm{m}^{-2}$.

Fig. 12. Same as Fig. 11 but extended to all models analyzed in this thesis. Models from top of first column: HadGEM1, MRI, GISS, IPSL, HadCM3, CCSM3, MIROC, INM CM3. Scale is from 0 to $350 \mathrm{~kg} \mathrm{~m}^{-2}$. 
Fig. 13. Spatial distribution of monthly (P-E) simulated by HadGEM1 (top) and MRI (bottom) models averaged over GRACE obs period. Scale is from -35 to $35 \mathrm{~mm}$.

Fig. 14. Same as Fig. 13 but extended to all models analyzed in this thesis. Models from top of first column: HadGEM1, MRI, GISS, IPSL, HadCM3, CCSM3, MIROC, INM CM3. Scale is from -35 to $35 \mathrm{~mm}$. .36

Fig. 15. Spatial distribution of monthly SM within upper 0.1 meters as simulated by seven of the eight models analyzed in this thesis and averaged over the GRACE observational period. Models from top of first column: HadGEM1, MRI, GISS, (IPSL not available), HadCM3, CCSM3, MIROC, INM CM3. Scale is from 0 to $56 \mathrm{~kg} \mathrm{~m}^{-2}$. .38

Fig. 16. Time series of annual average SM in the MSRB with trend lines for HadGEM1 (black) and MRI (teal) over the $21^{\text {st }}$ century for the A2 scenario......41

Fig. 17. Difference plot of SM for HadGEM1 showing the last decade of the $21^{\text {st }}$ century minus the first decade. Blue areas indicate a moistening trend, while red areas with dotted contour lines indicate a drying trend. Scale is from -350 to $350 \mathrm{~kg} \mathrm{~m}^{-2}$.

Fig. 18. Difference plot of SM for MRI showing the last decade of the $21^{\text {st }}$ century minus the first decade. Blue areas indicate a moistening trend, while red areas with dotted contour lines indicate a drying trend. Scale is from -350 to $350 \mathrm{~kg} \mathrm{~m}^{-2}$

Fig. 19. Difference plot of P for HadGEM1 (top) and MRI (bottom) showing the last decade of the $21^{\text {st }}$ century minus the first decade. Scale is from -70 to $70 \mathrm{~kg} \mathrm{~m}^{-2}$

Fig. 20. Difference plot of E for HadGEM1 (top) and MRI (bottom) showing the last decade of the $21^{\text {st }}$ century minus the first decade. Scale is from -70 to $70 \mathrm{~kg} \mathrm{~m}^{-2}$......

Fig. 21. Difference plot of (P-E) for HadGEM1 (top) and MRI (bottom) showing the last decade of the $21^{\text {st }}$ century minus the first decade. Scale is from -70 to $70 \mathrm{~kg} \mathrm{~m}^{-2}$

Fig. 22. Multi-model mean annual SM anomaly composite (dashed blue line), versus GRACE composite (solid black line) for the eight models listed in Table 1. Gray shading shows range of SM anomalies projected by individual models. Based on the results shown in Fig. 4.

Fig. 23. Top (a): $21^{\text {st }}$ century time series of annually-averaged SM for all eight models analyzed with multi-model mean. Bottom (b): $21^{\text {st }}$ century time series with multi-model mean of annually-averaged SM for six models, excluding IPSL and MIROC from the original eight. 


\section{LIST OF TABLES}

Table 1. IPCC models analyzed in this study, including model sensitivity and grid resolution. IPCC models with bucket hydrology models were not examined.

Table 2. Models ranked by correlation $(r)$ between model annual cycle of TWS composite and GRACE-derived TWS composite during the GRACE observational period. Bolded model shows best correlation.

Table 3. Models ranked by residual area between model annual cycle of TWS composite curve and GRACE TWS composite curve during the GRACE observational period. Bolded model shows smallest area difference.

Table 4. Models ranked by ratio of area under each model's composite curve to area under GRACE composite curve. A value of 1.0 represents the best fit possible. Bolded models show those with amplitude ratios closest to 1.0 .......20

Table 5. HadGEM1 annual SM anomaly composites tested against GRACE. From left: composited time period starting in May of first year to November of last year; HadGEM1 correlation to GRACE; HadGEM1 residual area from GRACE; HadGEM1 amplitude ratio to GRACE.

Table 6. Land model resolution description for each model analyzed (PCMDI 2010, see Model Documentation).

Table 7. Average values of SM, P, E, and R for the MSRB over the GRACE observational period for HadGEM1, MRI, IPSL, and MIROC.

Table 8. From left to right: model name; model correlation with GRACE (from Section 3); SM trend from 2000-2100 with uncertainty calculated at the 95\% confidence level (bolded indicates significance); the mean difference of projected SM between the last decade and the first decade of the $21^{\text {st }}$ century with uncertainty calculated at the 95\% confidence level (bolded indicates significance). Arranged by most positive trend at top.

Table 9. $21^{\text {st }}$ century trends of $\mathrm{P}, \mathrm{E}$, and (P-E) for all models analyzed in this thesis. Trends are in $\mathrm{kg} \mathrm{m}^{-2}$ decade $^{-1}$, and bolded text indicates statistical significance at the $95 \%$ confidence level. 


\section{Introduction and literature review of GRACE satellite data and IPCC model data \\ a. Overview}

The Mississippi River Basin (MSRB) is the fourth largest river basin in the world, and the land has been used mainly for agriculture for the past 200 years (NPS 2011, http://www.nps.gov/miss/riverfacts.htm). Within this basin, $92 \%$ of the nation's agricultural exports are produced as well as $78 \%$ of the world's exports in livestock feed grains and soybeans (NPS 2011). Most of the nation's livestock and hogs also come from this area (NPS 2011). Due to the agricultural importance of this basin, it is critical to assess how MSRB water resources might be affected by climate change. Further, soil moisture (SM) is a key supply source of natural water for agriculture and natural vegetation (Robock et al. 2000).

In this thesis, we analyze water storage trends for the $21^{\text {st }}$ century in the MSRB using simulated SM content from select models used within the Intergovernmental Panel on Climate Change (IPCC) Fourth Assessment Report (AR4) (Solomon et al. 2007). Total water storage (TWS) anomaly data from the Gravity Recovery and Climate Experiment (GRACE) are first used to validate IPCC modeled SM over the period of May 2002 to November 2009.

\section{b. Background information}

The IPCC AR4 is based upon examination of output from 23 models, each running multiple simulations of future climate under different greenhouse gas emission scenarios. There are significant variations between each model's physics, including the surface hydrology (land) models. This leads to uncertainty in the reliability of simulated 
variables, including SM (Randall et al. 2007). One of the main functions of the planet's land surface is to collect SM and control its evaporation back into the atmosphere (Randall et al. 2007). In the past, modelers treated SM as a tuning parameter to ensure reasonable simulated values of evapotranspiration and runoff (Robock et al. 2000). With this tuning, global climate modelers could adjust the heat and water fluxes from the land model to make the atmospheric solution above more realistic. However, this resulted in poor estimates of the actual amount of moisture in the soil (Robock et al. 2000).

In the AR4, much improvement has been made by modelers to include more advanced terrestrial processes such as carbon cycle dynamics, plant root parameterization, river routing, multi-layer snow packs, and coupling of ground water models into land surface schemes (Randall et al. 2007). Even so, there have been few assessments between the Third and Fourth IPCC Assessment Reports to validate modelsimulated SM with observations. Randall et al. (2007) point out that it is not obvious how to compare simulated SM with remotely sensed SM, which makes it difficult to assess how well climate models simulate SM and the change in SM in future scenarios. Since the AR4 release, and with the increase of remote-sensing instruments to provide indirect estimates of SM, along with new measurement techniques, there have been an increasing number of published works validating SM datasets, and comparing these SM datasets to regional and global climate models (GCMs) (Seneviratne et al. 2010). The analysis presented in this thesis attempts to validate simulated SM calculated by several IPCC models using the satellite remotely-sensed data from GRACE. 
The GRACE mission was begun when twin satellites, GRACE-A and GRACE-B (CSR 2012, http://www.csr.utexas.edu/grace/asdp.html), were launched in March of 2002 as a collaboration between the U.S. and German space agencies, NASA and DLR, respectively (JPL 2011a, http://podaac.jpl.nasa.gov/gravity/grace). These satellites detect changes over time in Earth's gravity field. These observations in turn yield observations of changes in TWS, ice mass variations, ocean bottom pressure changes, and sea level variations (JPL 2011a). The gravity data are derived from a K-band microwave ranging system that measures the distance changes between the two identical satellites as they orbit the Earth in tandem at approximately $220 \mathrm{~km}$ apart from one another and at a nominal altitude of $485 \mathrm{~km}$ (GSFC 2003; Rodell et al. 2007). This distance changes when the satellites are affected by perturbations in the Earth's gravity field (GSFC 2003). These perturbations may be caused by large mass features, including mountains and oceans, which have different gravitational pulls, causing the satellites' orbits to speed up or slow down as they fly overhead (GSFC 2003; Rodell et al. 2007). The rates at which the inter-satellite distance changes over time provide highly accurate global gravity field solutions (Rodell et al. 2007). Each solution is in the form of a series of coefficients for a spherical harmonic expansion, which is used to describe the shape of the gravity field (Rodell et al. 2007). Non-hydrological processes that contribute to the gravitational perturbations, such as atmospheric and oceanic circulations and solid Earth tides, are removed from GRACE level 2 products (e.g., using reanalysis data to remove the atmospheric mass component). Finally, the mass anomalies for a certain region, expressed as equivalent heights of water, can be calculated due to the direct relationship 
between gravity and mass (Rodell et al. 2007). These satellites can detect mass changes below the surface, so GRACE data are therefore more accurate in detecting TWS changes than data gathered by typical field instruments (Rodell 2008).

GRACE data are collected, processed, and made available through the mission partners: University of Texas Center for Space Research (CSR), the GeoForschungsZentrum (GFZ) Potsdam, and the Jet Propulsion Laboratory (JPL) (JPL 2011a). This thesis uses data from the CSR, as will be discussed further in Section 2. Many previous studies have compared GRACE data to observations of TWS components (ice, snow, surface water, SM, groundwater), as well as to output from hydrological models (Ramillien et al. 2008; Seneviratne et al. 2010). Examples include TWS change in the San Joaquin and Sacramento River basins (Ho 2009), TWS depletion in Central Europe (Anderson et al. 2005), groundwater monitoring in the High Plains aquifer in the Central US (Rodell and Famiglietti 2002), and estimation of groundwater change in the MSRB (Rodell et al. 2007). These studies have shown that GRACE can accurately detect changes in TWS. Changes in the components of TWS, such as groundwater, can also be derived. As a result of these and similar studies, we assume here that GRACE can be used as a proxy for observed TWS anomaly values.

In the mid-latitudes, TWS variability is due mainly to changes in SM (Rodell 2008), which is the water stored in the unsaturated soil zone (Seneviratne et al. 2010). An analysis by Rodell and Famiglietti (2001) of TWS in Illinois, which is within the MSRB, show that changes in SM are the largest contributor to the change in TWS, with groundwater-induced changes being of secondary importance; groundwater is the water 
stored in the deeper saturated soil zone (Swenson and Wahr 2009). Rodell et al. (2007) speculate that this holds true for the entire MSRB, and further determine that annual SM changes can be a good indicator of annual changes in deeper water storage (Rodell and Famiglietti 2001). In this thesis, we therefore compare GRACE TWS anomaly data to SM simulations from IPCC models for the MSRB.

Of the IPCC models with simulated SM data archived (not all models archive this quantity), we examine those models that do not use a bucket hydrology model. The bucket model is a simple land surface model where the land surface is characterized by the surface temperature, and the SM is contained in a single store, or "bucket" (Cox et al. 1999). Runoff occurs when the bucket is filled to capacity and then overflows, such as when the precipitation rate is greater than the evaporation rate (Cox et al. 1999). The bucket method ignores the impacts that vegetation and soil types have on heat, water, and momentum fluxes to the atmosphere, and has been shown to overestimate the likelihood of drought (Cox et al. 1999; Randall et al. 2007). Land models with multiple ground layers and a simple canopy scheme are expected to be more accurate because they have more realistic representations of the components of the hydrological cycle (Randall et al. 2007). As a result, in this thesis we compare GRACE TWS anomaly data to the SM simulations from those IPCC models that have more advanced land surface schemes than the bucket scheme.

The SM distributions presented in this thesis are from models using the IPCC SRES A2 scenario. This scenario assumes a world wherein nations are self-reliant, renewable energy is slow to develop, and the population continues to increase 
(Nakicenovic et al. 2000; Meehl et al. 2007a). These actions cause $\mathrm{CO}_{2}$ emissions to continue rising and end with a globally-averaged projected temperature increase of about $3.6^{\circ} \mathrm{C}$ by the year 2100 (Meehl et al. 2007a). The A2 scenario is one that projects some of the highest greenhouse gas emissions when compared to other IPCC scenarios, and so it is used to illustrate a possible worst-case scenario if measures are not taken by society to curb the amount of greenhouse gases emitted. We note that recent observations indicate that emissions are already exceeding the emission levels of the IPCC SRES A2 scenario (Allison et al. 2009; Betts et al. 2009; Raupach and Fraser 2011).

The IPCC models analyzed in this thesis have grid resolutions varying between $1.25^{\circ}$ and $4^{\circ}$ in latitude and between $1.4^{\circ}$ and $5^{\circ}$ in longitude. Due to the coarse resolution of these models, only an area large enough to encompass numerous IPCC model grid points for averaging would give accurate regional results. Furthermore, TWS changes are detectable by GRACE only in all months of the year for areas of 500000 $\mathrm{km}^{2}$ and larger, with the relative uncertainty of the TWS values decreasing as the area increases (Rodell and Famiglietti 2001). Hence, the MSRB, which is about 3.2 million $\mathrm{km}^{2}$ in area (NPS 2011), is of ample size for analysis in this thesis (Rodell et al. 2007; Rodell and Famiglietti 2001). Figure 1 shows that the HadCM3 model, which has a grid resolution approximately in the middle of the resolution ranges mentioned above, has 38 grid points (red diamonds) within the MSRB (blue outline). 


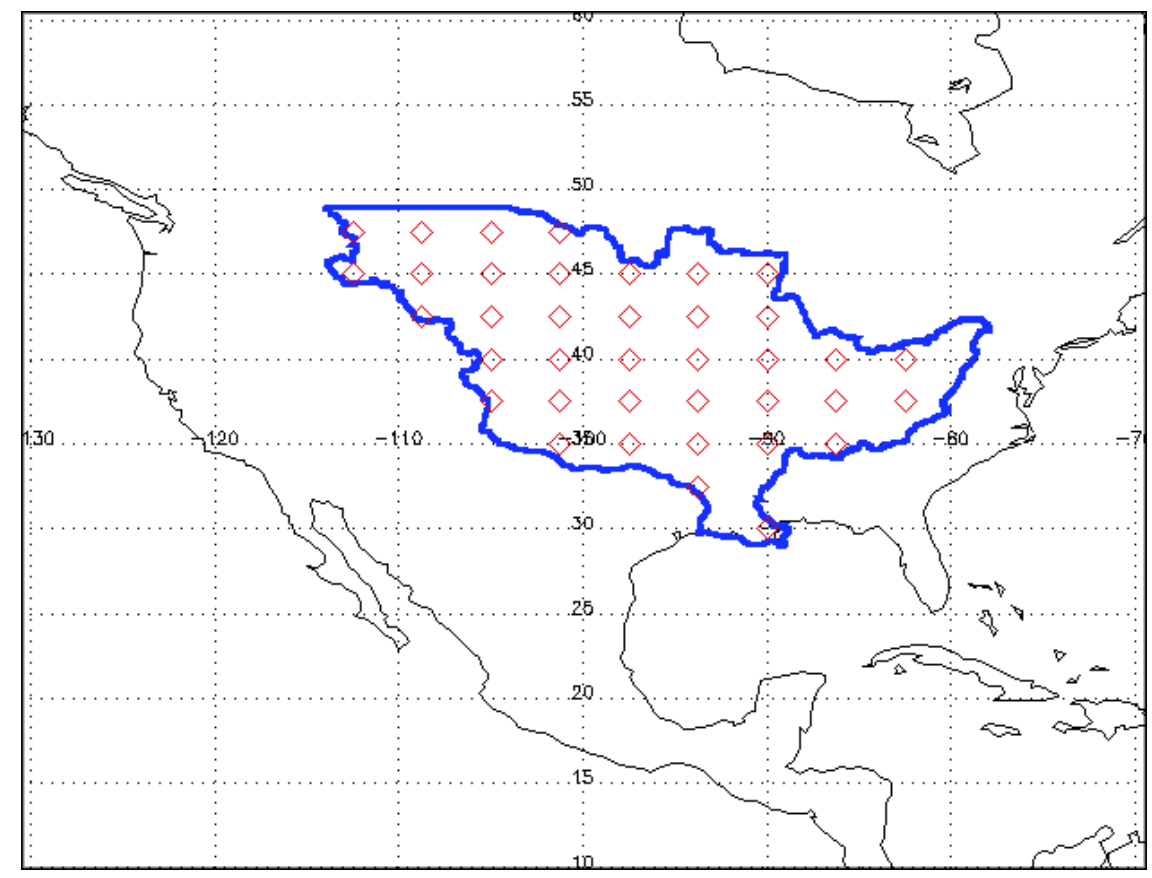

Fig. 1. HadCM3 model grid points (red diamonds) encompassed within the MSRB (outlined in blue).

\section{c. Project goals}

The main goal of this thesis is to examine SM trends in the MSRB as simulated by IPCC models over the $21^{\text {st }}$ century. An important initial task is to check the reliability of the model-simulated SM distributions in the early $21^{\text {st }}$ century by comparing them to GRACE satellite observations of TWS anomalies for the MSRB.

It is unclear whether increased precipitation $(\mathrm{P})$ and/or evaporation (E) should be expected over the next century in the MSRB, and thus whether TWS, which is roughly (P-E), will increase or decrease. Meehl et al. (2007a) explain that a future warmer climate will experience increased summer drying with increased evaporation in the midlatitudes, leading to increased risk of drought. This could cause regional vegetation to dry up and die off, which in turn could increase the area of land experiencing drought. At 
the same time, they note that precipitation events are expected to become more intense. This would increase the risk for flooding, with longer dry periods between the events. Meehl et al. (2007a) discuss how these projections also depend on latitude. IPCC model simulations show that for the subtropics and lower mid-latitudes, longer periods of dry days will occur between precipitation events. At higher mid-latitudes and high latitudes, where mean precipitation is expected to increase, there are projections of decreased periods of dry days.

Specifically for the United States, Anderson et al. (2009) explain that average precipitation has increased from $1958-2007$ by about $7 \%$, but heavy precipitation (defined as the heaviest $1 \%$ of all daily events) has increased in intensity and frequency by roughly $20 \%$, particularly in the Northeast and Midwest. They show that across the MSRB area, this heavy precipitation increase ranges from $15 \%$ to $31 \%$. Climate models project a continued increase in heavy precipitation for the United States during the $21^{\text {st }}$ century (Anderson et al. 2009).

Anderson et al. (2009) also explain that there is no observed national average trend in drought but that regional variations show significant changes in the severity and spread area of droughts due to temperature increases over the past 50 years. They show that within the MSRB, the majority of the significant drought trends have shown a decrease in drought, especially in the northern region of the basin. However, they also note that, with model-projected increases in frequency of heavy precipitation along with model-projected increases in the number of dry days between rain events, floods and droughts will become more intense and frequent on regional scales. 
It is generally accepted that the hydrological cycle will "speed up" as the climate warms, but the impacts on TWS in any given region are more complicated to predict. Consequently, it is difficult to hypothesize what the SM trend will be across the MSRB under a future warmer climate.

The methods for this study are described in Section 2, results are shown in Sections 3,4 , and 5, and a summary and discussion of the conclusions are presented in Section 6 .

\section{Methods}

a. GRACE

The GRACE TWS anomaly data were obtained from the University of Colorado GRACE website (University of Colorado 2010, http://geoid.colorado.edu/grace) for the MSRB for the time period May 2002 to November 2009, hereafter defined as the GRACE observational period. This particular data source was chosen due to the availability of GRACE data that are processed and averaged for significant river basins. The dataset analyzed in this thesis was produced by the CSR and is release number 04 DS. The data are spatially smoothed before release using a Gaussian smoother with radius $1000 \mathrm{~km}$. Smoothing is done to remove noisy short-wavelength spectral coefficients (University of Colorado 2010). This smoothing means that GRACE TWS anomaly data are valid for a region, not a point. A Gaussian smoothing radius of 1000 $\mathrm{km}$ has been shown to give TWS anomaly data accuracies equivalent to a water depth of up to $1.5 \mathrm{~cm}$ (Wahr et al. 2004). 
The GRACE data are compiled to a nominal monthly temporal resolution, with some months having several days of no data acquisition (JPL 2011b, http://gracetellus.jpl.nasa.gov/data/GraceMonths). Thus, for each IPCC model simulation, the GRACE data were interpolated in time to match the time resolution of the model so that a direct comparison could be made. A composite of the GRACE annual cycle over the 2002-09 period was then constructed to use in comparison with IPCC model SM output.

\section{b. IPCC models}

The IPCC GCMs analyzed in this project are listed in Table 1, along with each model's sensitivity and grid resolution. The climate sensitivity of a model is a value used to assess the response of the model to a given forcing. The sensitivity value is obtained by measuring the change in the global annual mean surface air temperature after doubling the atmospheric $\mathrm{CO}_{2}$ concentration and letting the model run to a new temperature equilibrium (Randall et al. 2007). Take, for example, that the atmospheric $\mathrm{CO}_{2}$ in a model is doubled from the industrial period amount of about $280 \mathrm{ppm}$ to $560 \mathrm{ppm}$, and the surface air temperature starts at $290 \mathrm{~K}$. After about 400 years of this model run under the doubled $\mathrm{CO}_{2}$ amount, the temperature increases and stabilizes at $292.5 \mathrm{~K}$. That climate model's sensitivity value is then $2.5 \mathrm{~K}$ ( or $^{\circ} \mathrm{C}$ ) - the difference between the initial surface air temperature and the stabilized surface air temperature after doubling $\mathrm{CO}_{2}$. 
Table 1. IPCC models analyzed in this study, including model sensitivity and grid resolution. IPCC models with bucket hydrology models were not examined.

\begin{tabular}{cccc}
\hline \multirow{2}{*}{ Model } & $\begin{array}{c}\text { Sensitivity } \\
\left({ }^{\circ} \mathbf{C}\right)\end{array}$ & $\begin{array}{c}\text { Grid Resolution } \\
\left({ }^{\circ}\right)\end{array}$ & $\begin{array}{c}\text { Longitude } \\
\left({ }^{\circ}\right)\end{array}$ \\
\hline UKMO-HadGEM1 & 4.4 & 1.25 & 1.88 \\
IPSL-CM4 & 4.4 & 2.53 & 3.75 \\
MIROC3.2-medres & 4.0 & 2.79 & 2.81 \\
UKMO-HadCM3 & 3.3 & 2.50 & 3.75 \\
MRI-CGCM2.3.2 & 3.2 & 2.79 & 2.81 \\
GISS-ER & 2.7 & 4.00 & 5.00 \\
CCSM3 & 2.7 & 1.40 & 1.41 \\
INM-CM3.0 & 2.1 & 4.00 & 5.00 \\
\hline
\end{tabular}

Model-projected SM data were collected from the World Climate Research Programme's (WCRP's) Coupled Model Intercomparison Project phase 3 (CMIP3) multimodel dataset for the aforementioned models assuming the A2 scenario for the $21^{\text {st }}$ century (PCMDI 2010, http://www-pcmdi.llnl.gov/ipcc/about_ipcc.php). Specifically, in this thesis we compare GRACE TWS anomaly data to IPCC models' monthly-averaged simulations of the soil moisture content, which sums the water present in all layers of the soil model and averages it over the land area of each grid cell (Meehl et al. 2007b).

Since we are comparing IPCC model-simulated SM to observed TWS for the MSRB, the following is a brief explanation of the relationship between these two variables. Volumetric soil moisture, $\theta\left(\mathrm{m}^{3}{ }_{\mathrm{H} 2 \mathrm{O}} \mathrm{m}^{-3}\right.$ soil $)$, is defined as the volume of liquid water per unit volume of soil (Seneviratne et al. 2010). It is a point-wise variable. Instead, the model-simulated soil moisture content $\left(\mathrm{kg}_{\mathrm{H} 2 \mathrm{O}} \mathrm{m}^{-2}\right.$ soil $)$ in the CMIP3 dataset is a depth-integrated variable, expressing the total soil moisture content over all soil layers 
in a given model. Volumetric soil moisture $(\theta)$ is thus related to soil moisture content (SM) by,

$$
S M=\int_{0}^{z_{w t}} \rho_{w} \theta d z,
$$

where $\mathrm{z}_{\mathrm{wt}}(\mathrm{m})$ is the depth of the lowest soil layer for each model, and $\rho_{\mathrm{w}}$ is the density of water $\left(1000 \mathrm{~kg} \mathrm{~m}^{-3}\right)$. Note that $\mathrm{SM}$ can be equivalently expressed in units of millimeters $(\mathrm{mm})$ of water by multiplying it by the density of water. This is convenient as precipitation, the main source term in the moisture balance equation, is typically expressed in depth units (e.g., millimeters or inches). As explained before, the change in SM in the MSRB is a good indicator of overall terrestrial water storage change (Rodell and Famiglietti 2001, Rodell et al. 2007). Thus, we compare the IPCC model-simulated SM to observed TWS anomalies from GRACE.

The conservation equation for total terrestrial water storage change, which is what GRACE measures, is given by (Seneviratne et al. 2010),

$$
\frac{d S}{d t}=P-E-R_{S}-R_{g},
$$

where $\mathrm{dS} / \mathrm{dt}$ is the TWS change, $\mathrm{P}$ is precipitation, $\mathrm{E}$ is evapotranspiration, $\mathrm{R}_{\mathrm{s}}$ is surface runoff, and $\mathrm{R}_{\mathrm{g}}$ is drainage. The $\mathrm{dS} / \mathrm{dt}$ term includes all forms of water storage, such as soil moisture, groundwater, snow, and water stored in biomass.

A river basin shapefile (NCL 2010, http://www.ncl.ucar.edu/Applications /shapefiles.shtm) was used to determine the boundary of each model's grid points at which SM values would be selected for averaging across the river basin. From these 100year simulations assuming the A2 scenario, the annual cycles of basin-averaged SM were then computed and an annual composite formed for each model for the GRACE 
observational period, May 2002 to November 2009. The IPCC model composites were then compared to the GRACE composite discussed above and are discussed below in Section 3. The correlations between GRACE and the models are generally good, giving some confidence in the basin-averaged simulated SM for the 2002-09 period.

Statistical analyses were then performed on the model-simulated SM annuallyaveraged data for the entire $21^{\text {st }}$ century. First, SM trends were calculated with autocorrelation to the $95 \%$ confidence level. Second, the average SM distribution of the last decade of the $21^{\text {st }}$ century was compared to that of the first decade. We looked for statistically significant differences between these decades. Actual SM values and distributions across the MSRB were also examined and compared to observations.

\section{GRACE validation of IPCC models}

Our first step is to use GRACE data to validate present-day simulations of SM by the IPCC suite. As mentioned above, enough analysis of GRACE data has been done to convince us that GRACE data can serve as an accurate proxy for observed TWS anomaly values. Because TWS changes in the mid-latitudes are mainly due to changes in SM, we can therefore compare the GRACE data to IPCC simulations of SM.

a. GRACE

A time series of the GRACE TWS monthly anomaly data for the MSRB is shown in Fig. 2. This is the time-interpolated data set used for direct comparison to each IPCC model. The data show an upward trend of $39.46 \pm 9.28 \mathrm{~mm} \mathrm{decade}^{-1}$ (significant at the $95 \%$ confidence level, accounting for autocorrelation). The data were gathered over just under eight years, and there is substantial year-to-year variability. An average or 
composite of the annual cycle will serve better in comparison to the IPCC model data, as opposed to solely a trend comparison.

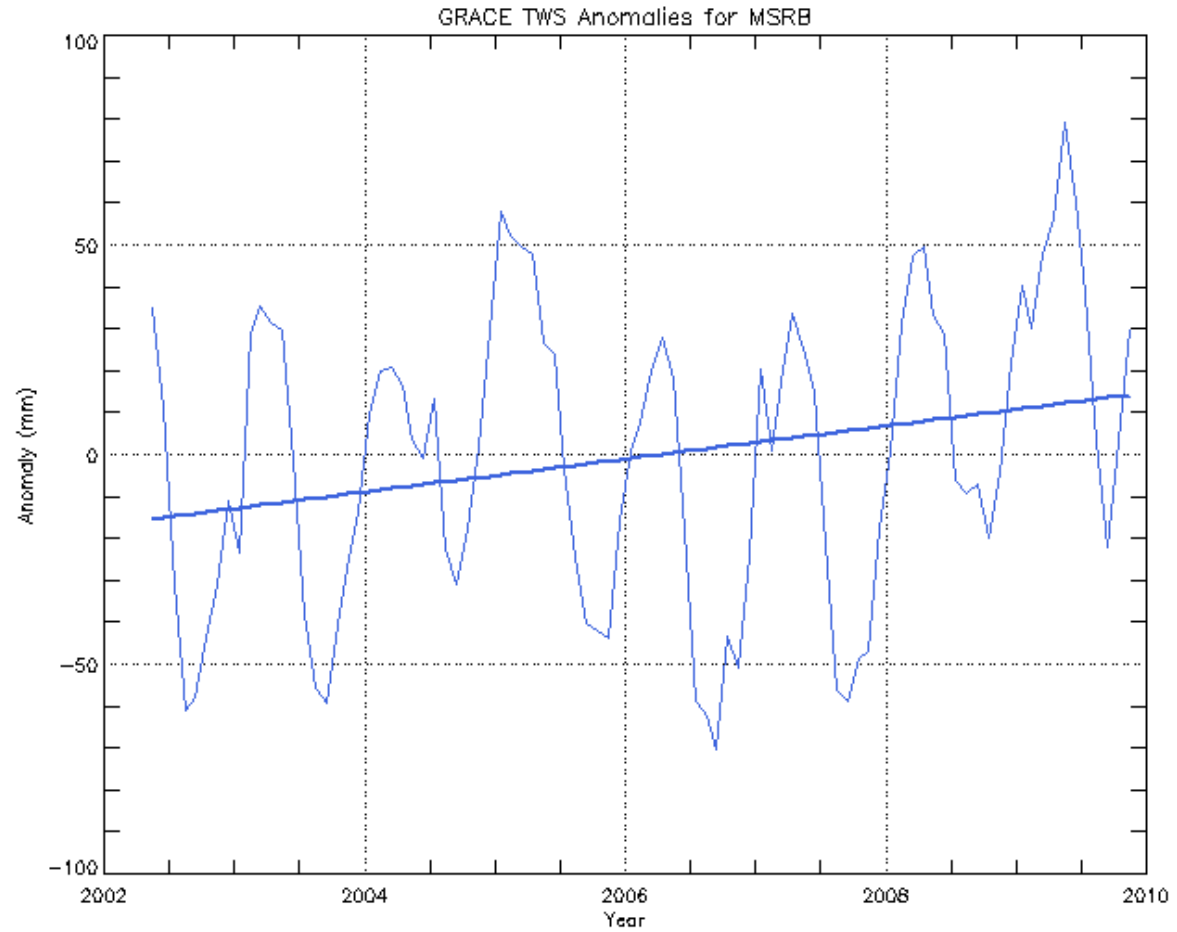

Fig. 2. Time series of GRACE monthly TWS anomaly data averaged across the MSRB with trend line.

The eight annual cycles of GRACE TWS anomalies averaged over the MSRB for each year during the GRACE observational period are shown in Fig. 3. The eight-year composite is shown in the thick, black line. The composite has a peak in April of about $+35 \mathrm{~mm}$, while the minimum is in September with a value of about $-45 \mathrm{~mm}$. There is considerable year-to-year variability with TWS anomaly peaks as high as $+80 \mathrm{~mm}$, and minima of $-70 \mathrm{~mm}$. Although the average peak occurs in April, the peaks for individual 
years range from January (2005) to May (2009). Similarly, the average minimum occurs in September, but this ranges from August (2002) to November (2005).

This seasonal cycle showing a maximum in spring and minimum in fall compares well with expectations. Precipitation (P) across the MSRB has its maximum in the late spring and early summer months, and its minimum during the winter months (see e.g., Music and Caya 2007, Fig. 4). Evaporation (E) is radiatively-driven, and so is largest in summer and minimal in winter (Music and Caya 2007). During spring therefore, $\mathrm{P}>\mathrm{E}$, and the TWS maximum should coincide with the annual peak in cumulative (P-E). In the late summer to fall months, $\mathrm{E}>\mathrm{P}$, and minimum TWS should coincide with the annual minimum cumulative (P-E). With a minimum in both $\mathrm{E}$ and $\mathrm{P}$ during winter, water storage change is small at that time of year. 


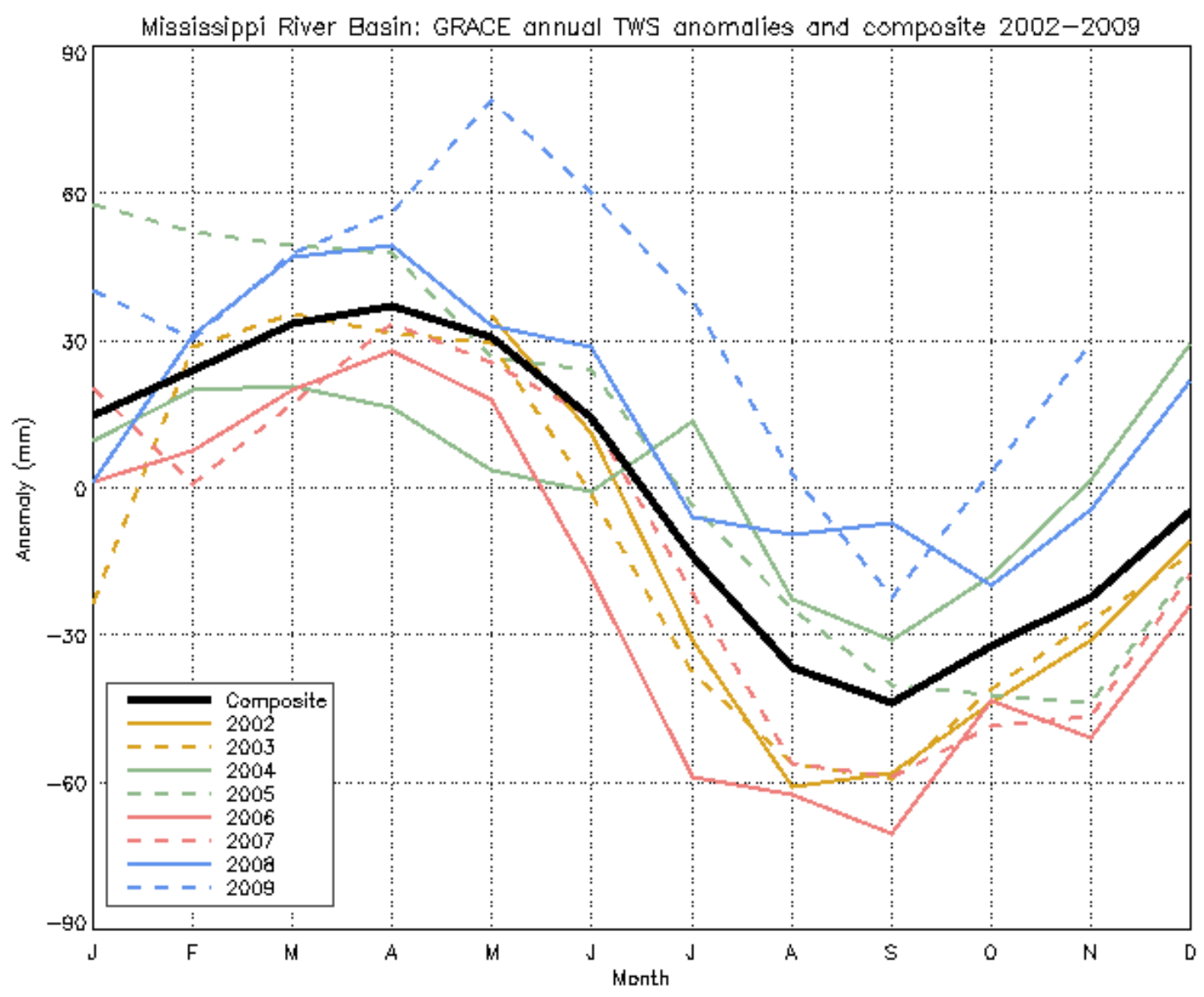

Fig. 3. Annual cycles of GRACE-derived TWS anomaly for the MSRB for the period May 2002 to November 2009, with composite shown by the thick, black line.

\section{b. IPCC models}

1) ANNUAL CyCLE ANOMALy COMPOSITE

As discussed in Section 2b, we constructed a composite annual cycle of SM averaged over the MSRB for each of the selected IPCC models. This was done for the GRACE observational period of May 2002 to November 2009, and assumed the A2 scenario. The eight simulated cycles are shown in Fig. 4, along with the observed GRACE composite (same black line as in Fig. 3). 


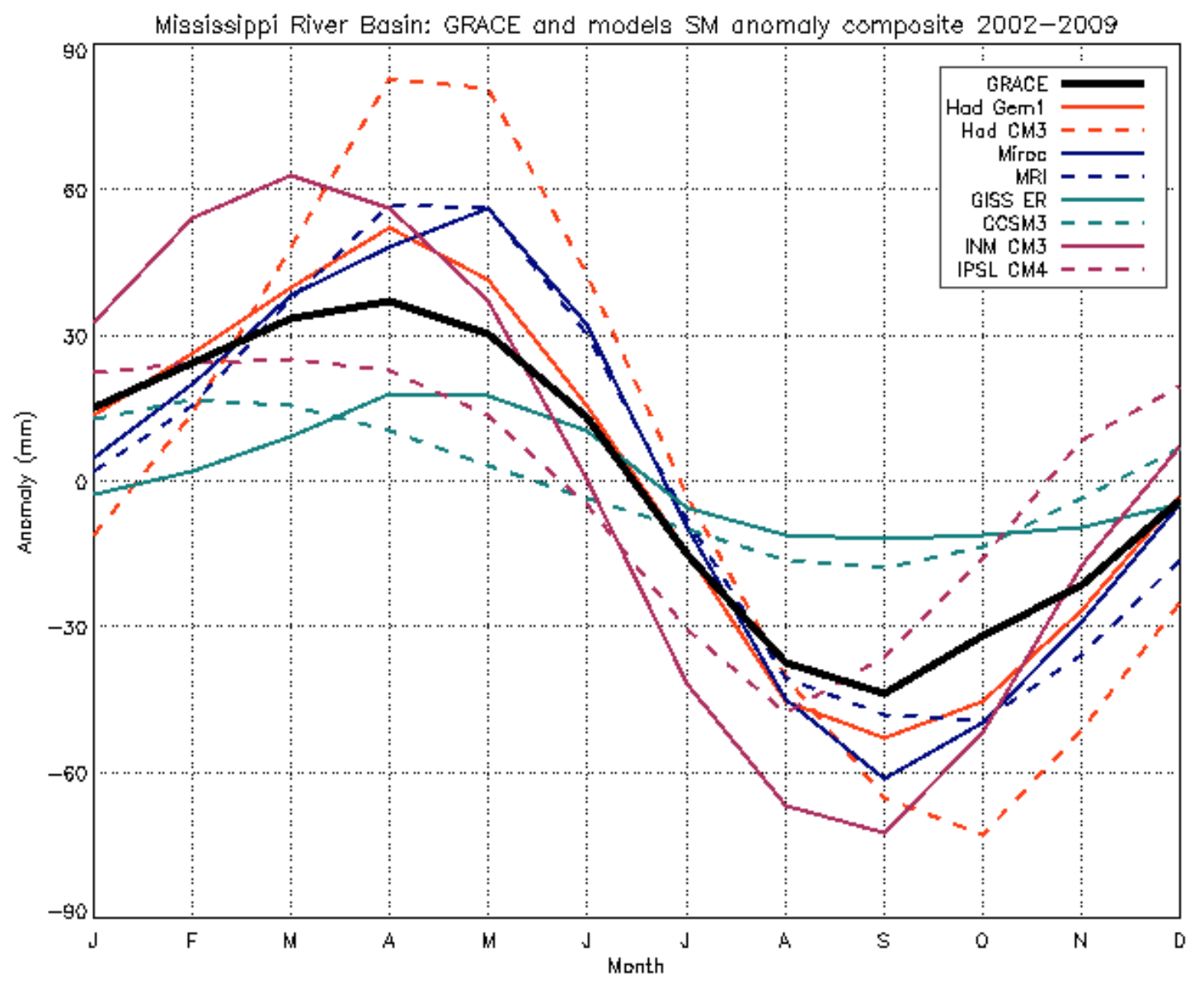

Fig. 4. Annual cycle of model SM anomaly for each of the models analyzed in this study for the MSRB over the simulated period May 2002 to November 2009. Also shown is the corresponding GRACE TWS anomaly composite.

Model composited values generally show good seasonal timing in comparison to GRACE (i.e., observations). The models bolded in Tables 2-4 show those that rank the best in each of the following comparison tests. In Table 2 we show the models ranked by the correlation between model monthly SM anomaly values over the MSRB and GRACE composite anomaly values over the same location and period. Correlation values range from 0.83 to 0.99 , with the HadGEM1 model (solid orange line in Fig. 4) performing best by this measure. While the timing of the composited model annual anomaly cycles 
generally compare well to observations, there are significant amplitude differences between the models' SM and the GRACE observations. For example, the HadCM3 model appears to overestimate the seasonal cycle by a factor of about two, whereas the CCSM3 model underestimates the amplitude by a factor of about two. There is also some model-to-model variability in the timing of annual maxima and minima.

Table 2. Models ranked by correlation $(r)$ between model annual cycle of TWS composite and GRACE-derived TWS composite during the GRACE observational period. Bolded model shows best correlation.

\begin{tabular}{cc}
\hline \hline Model & GRACE $\boldsymbol{r}$ \\
\hline UKMO-HadGEM1 & $\mathbf{0 . 9 9 4}$ \\
MIROC3.2-medres & 0.972 \\
INM-CM3.0 & 0.966 \\
MRI-CGCM2.3.2 & 0.950 \\
UKMO-HadCM3 & 0.900 \\
GISS-ER & 0.896 \\
CCSM3 & 0.882 \\
IPSL-CM4 & 0.832 \\
\hline
\end{tabular}

To account for the amplitude differences, the area difference between each model's composite curve and the GRACE composite curve was calculated. These area differences roughly represent how many millimeters per year a model's annual composite differs from the GRACE annual composite. However, these do not show if the model is over- or under-estimating the observed amount. The results (Table 3) show values ranging from 75.5 to 305 . Smaller values are better as they indicate smaller differences between the model and GRACE. As the results show, the HadGEM1 model performs best by this measure as well. 
Table 3. Models ranked by residual area between model annual cycle of TWS composite curve and GRACE TWS composite curve during the GRACE observational period.

Bolded model shows smallest area difference.

\begin{tabular}{cc}
\hline \hline Model & Residual area \\
\hline UKMO-HadGEM1 & $\mathbf{7 5 . 5}$ \\
MIROC3.2-medres & 133.4 \\
MRI-CGCM2.3.2 & 147.3 \\
IPSL-CM4 & 168.3 \\
CCSM3 & 196.8 \\
GISS-ER & 200.2 \\
INM-CM3.0 & 235.7 \\
UKMO-HadCM3 & 305.0 \\
\hline
\end{tabular}

Lastly, a ratio was calculated of the total area under each model curve to the total area under the GRACE curve. These ratios (Table 4) range from 0.37 to 1.75 , with values closest to 1.0 indicating the best match to GRACE. Values below 1.0 denote an underestimation from the observations, whereas values over 1.0 show an overestimation. The HadGEM1 model performs best, overestimating the amplitude of the composite by a factor of 1.23, whereas the IPSL model underestimates by a factor of 0.88 . Although the ratio for the IPSL model is closer to 1.0 than for the HadGEM1, Fig. 4 shows that the IPSL phasing is less accurately simulated, with the maximum and minimum occurring earlier in the year than the GRACE observations. The phase predicted by HadGEM1 is closer to the GRACE composite. Overall, there is a considerable spread of results, indicating a wide range of SM conditions simulated by these eight models. 
Table 4. Models ranked by ratio of area under each model's composite curve to area under GRACE composite curve. A value of 1.0 represents the best fit possible. Bolded models show those with amplitude ratios closest to 1.0.

\begin{tabular}{cc}
\hline Model & $\begin{array}{c}\text { Ratio } \\
\text { (model/GRACE) }\end{array}$ \\
\hline GISS-ER & 0.37 \\
CCSM3 & 0.43 \\
IPSL-CM4 & $\mathbf{0 . 8 8}$ \\
UKMO-HadGEM1 & $\mathbf{1 . 2 3}$ \\
MRI-CGCM2.3.2 & 1.29 \\
MIROC3.2-medres & 1.30 \\
INM-CM3.0 & 1.63 \\
UKMO-HadCM3 & 1.75 \\
\hline
\end{tabular}

Based on these comparisons between models and GRACE, the model that best represents the MSRB seasonal water storage average is HadGEM1, followed secondly by MRI. In making this statement, we have eliminated those models whose annual SM anomaly composite is out of phase with the GRACE composite, and also those models that have unrealistic spatial distributions (as will be discussed in the next section). As a result, the HadGEM1 and MRI models will be the focus of discussion for the remainder of this thesis. To summarize the comparisons between GRACE and these two models: the HadGEM1 model composite has a 0.99 correlation to the GRACE composite, a 75.5 area difference from GRACE, and an amplitude ratio of 1.23 compared to GRACE; the MRI model has a 0.95 correlation to the GRACE composite, an area difference of 147.3 (almost twice as large as the HadGEM1 model), and a higher amplitude ratio of 1.29 compared to GRACE.

To determine if HadGEM1 compares well with the GRACE observations only by chance, two more consecutive time periods - May 2010 to November 2017, and May 
2018 to November 2025 - were composited from the HadGEM1 A2 SM simulation and tested against the GRACE composite. This comparison is shown in Fig. 5. Again, the thick, black line displays the GRACE composite. Other than the 2010-17 spring peak occurring in May instead of April, the three HadGEM1 time period composites are very well in phase with GRACE, as shown by the 0.99 correlation values in Table 5 . The residual area values for each HadGEM1 time period composite show between 61 and 108 $\mathrm{mm}$, which are less than the values for the other models during the GRACE observational period (see Table 3). The HadGEM1 amplitude ratios vary between 1.12 and 1.33, showing that the model tends to slightly overestimate the amount of annual SM change. Overall, these three different HadGEM1 time period composite tests suggest that this model reproduces well the SM annual cycle in the MSRB. 


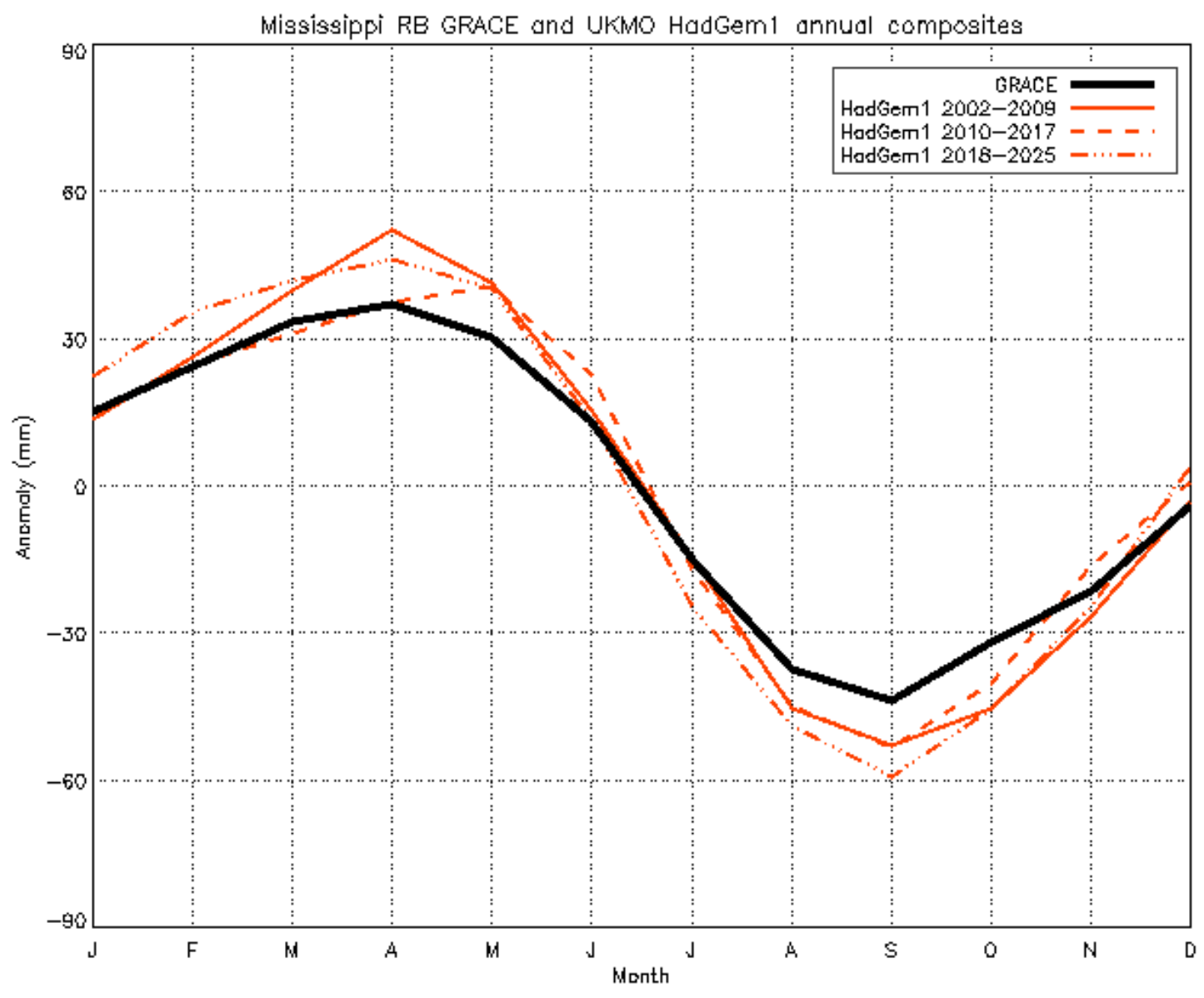

Fig. 5. HadGEM1 annual SM anomaly composites for the time periods May 2002 to November 2009, May 2010 to November 2017, and May 2018 to November 2025. GRACE composite is overlaid in thick, black line.

Table 5. HadGEM1 annual SM anomaly composites tested against GRACE. From left: composited time period starting in May of first year to November of last year; HadGEM1 correlation to GRACE; HadGEM1 residual area from GRACE; HadGEM1 amplitude ratio to GRACE.

\begin{tabular}{cccc}
\hline \hline HadGEM1 period & GRACE $\boldsymbol{r}$ & Resid. Area & Amp. Ratio \\
\hline $2002-2009$ & 0.994 & 75.5 & 1.23 \\
$2010-2017$ & 0.986 & 60.7 & 1.12 \\
$2018-2025$ & 0.995 & 107.7 & 1.33 \\
\hline
\end{tabular}


The wide range of SM simulations between each model could be due in part to the differences in each model's parameterizations for calculating the heat and water fluxes. The land model parameterizations in HadGEM1 assume four soil layers in which heat and water fluxes are computed. The MRI model uses three layers to compute heat and water fluxes. The land models within the other IPCC GCMs analyzed here have many different methods for computing heat and water fluxes through the soil, including different numbers of layers and "tiling" (Table 6). A "tile" represents a certain land cover type, and each land cover type has particular heat and water flux calculations associated with it (Dai et al. 2003). However, differences in layers and tiling do not obviously correspond to good or bad model performance in Fig. 4, or Tables 2-4 above.

Table 6. Land model resolution description for each model analyzed (PCMDI 2010, see Model Documentation).

\begin{tabular}{cr}
\hline \hline Model & Land Resolution \\
\hline UKMO-HadGEM1 & Up to 9 tiles. 4 layers for heat and water. \\
MIROC3.2-medres & Without tiling. 5 layers for heat and water. \\
UKMO-HadCM3 & One tile. 4 layers for heat and water. \\
GISS-ER & 6 layers. Thickness of upper layer 10cm, total depth $3.5 \mathrm{~m}$. \\
ERI-CGCM2.3.2 & 3 layers for heat and water. \\
IPSL-CM4 & 11 layers for heat transfer and 2 for water. \\
CCSM3 & 10 layers for heat and water. \\
INM-CM3.0 & Multiple land units (5 types available) per grid cell. \\
\end{tabular}




\section{2) Spatial Distributions OF SM}

We next examine the spatial distributions of SM simulated by the two IPCC models that best simulated the GRACE anomaly data in the MSRB - HadGEM1 and MRI. Figure 6 shows that during the GRACE observational period, the SM absolute values (as opposed to the anomalies which were discussed in previous sections) are very different between these two models. HadGEM1 shows a northwest to southeast gradient of SM values within the MSRB during the GRACE observational period, with values ranging from $300-400 \mathrm{~kg} \mathrm{~m}^{-2}$ in the northwest to $900-1000 \mathrm{~kg} \mathrm{~m}^{-2}$ in the southeast. The same is true for the two other HadGEM1 periods analyzed (2010-17 and 2018-25, not shown). A much wider spread of SM values is simulated by MRI, with values ranging from $0-100 \mathrm{~kg} \mathrm{~m}^{-2}$ in the west to $1100-1200 \mathrm{~kg} \mathrm{~m}^{-2}$ in the east. Thus, the MRI model is much drier in the west and wetter in the southeast than the HadGEM1 model.

Figure 7 shows the SM distributions for all eight models analyzed in this study. This shows the high variability in simulated SM distribution among these eight IPCC models. For instance, IPSL simulates a very dry SM distribution with all values in the U.S. under $300 \mathrm{~kg} \mathrm{~m}^{-2}$. MIROC has a very moist solution with all values in the range $700-1400 \mathrm{~kg} \mathrm{~m}^{-2}$ and higher. Both of these models have little spatial variation across the MSRB, and MIROC has a very wet solution for the northern Rockies. Similarly, INM CM3 shows little variation across the MSRB with total values ranging from $700-900 \mathrm{~kg}$ $\mathrm{m}^{-2}$. The other models show simulated SM distributions that are more consistent with observations (see below). However, it is notable that the eight solutions are very 
different from one another in the regional distributions and range of maximum and minimum values.

As GRACE only provides TWS anomaly data, we examined the NCEP North American Regional Reanalysis (NARR) dataset to get an estimate of the observed absolute values of SM down to a depth of 1.0 m (NOAA ESRL PSD 2011, http://www.esrl.noaa.gov/psd/data/gridded/data.narr.subsurface.html). The NARR monthly SM averaged over the period 1979-2010 is shown in Fig. 8a, and the 2002-09 average is shown in Fig. 8b. The 1979-2010 plot is indicative of the climatological average SM. The 2002-09 plot is very similar, spatially, to the climatology plot, showing that the 2002-09 NARR plot is representative of the long-term mean. This indicates that the NARR-GRACE data over the 2002-09 period are typical of the long-term SM pattern across the MSRB. A northwest to southeast gradient is apparent across the MSRB in both NARR plots, with low values ranging from about $200-300 \mathrm{~kg} \mathrm{~m}^{-2}$ in the northwest, and high values of about $600-700 \mathrm{~kg} \mathrm{~m}^{-2}$ in the southeast. 
Soil moisture (kg/mA2) (GRACE obs period) - UKMO Had Gem1 SRES A2 (run 1)
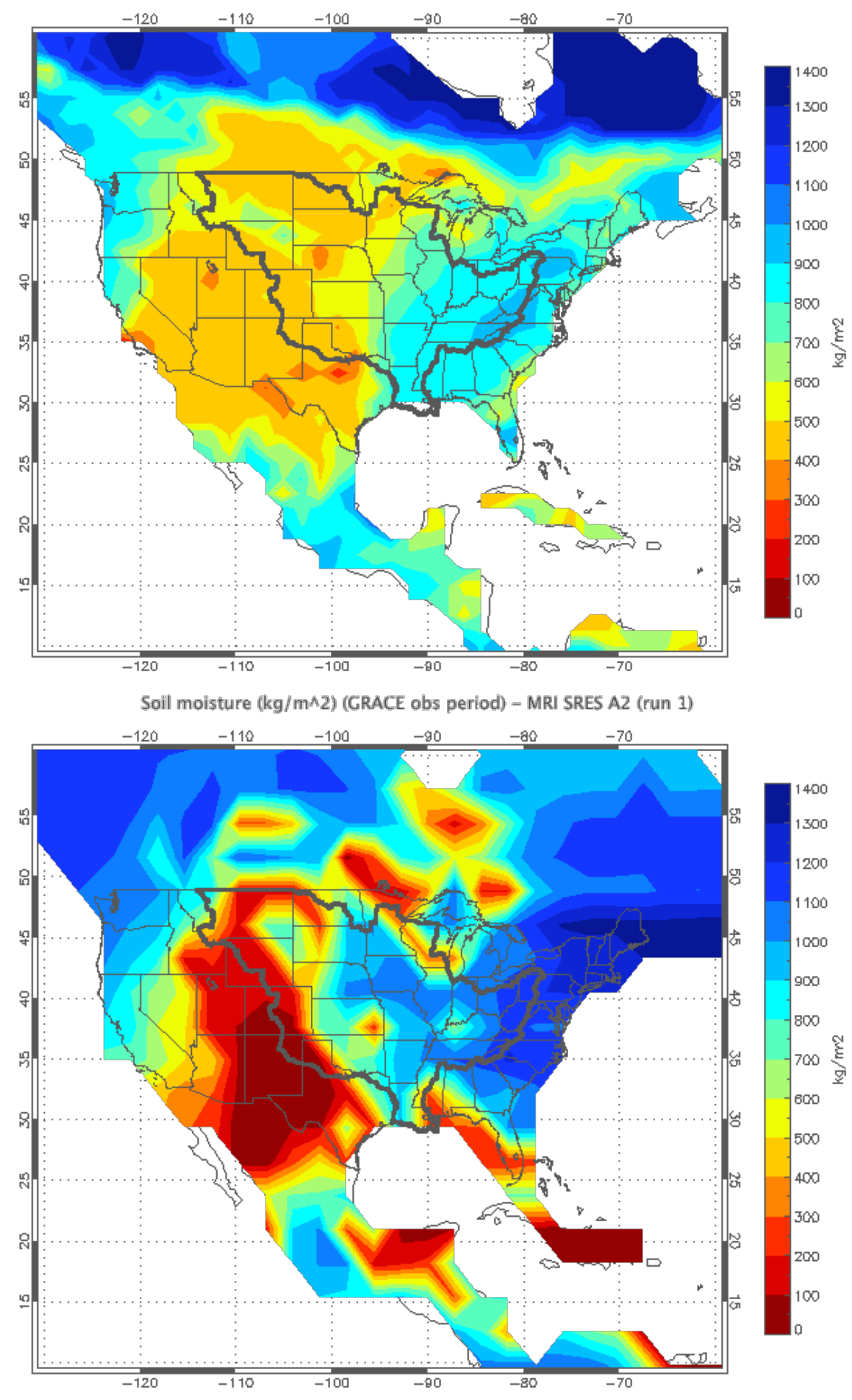

Fig. 6. Spatial distribution of SM simulated by HadGEM1 (top) and MRI (bottom) models averaged over GRACE observational period. Scale is from 0 to $1400 \mathrm{~kg} \mathrm{~m}^{-2}$. 

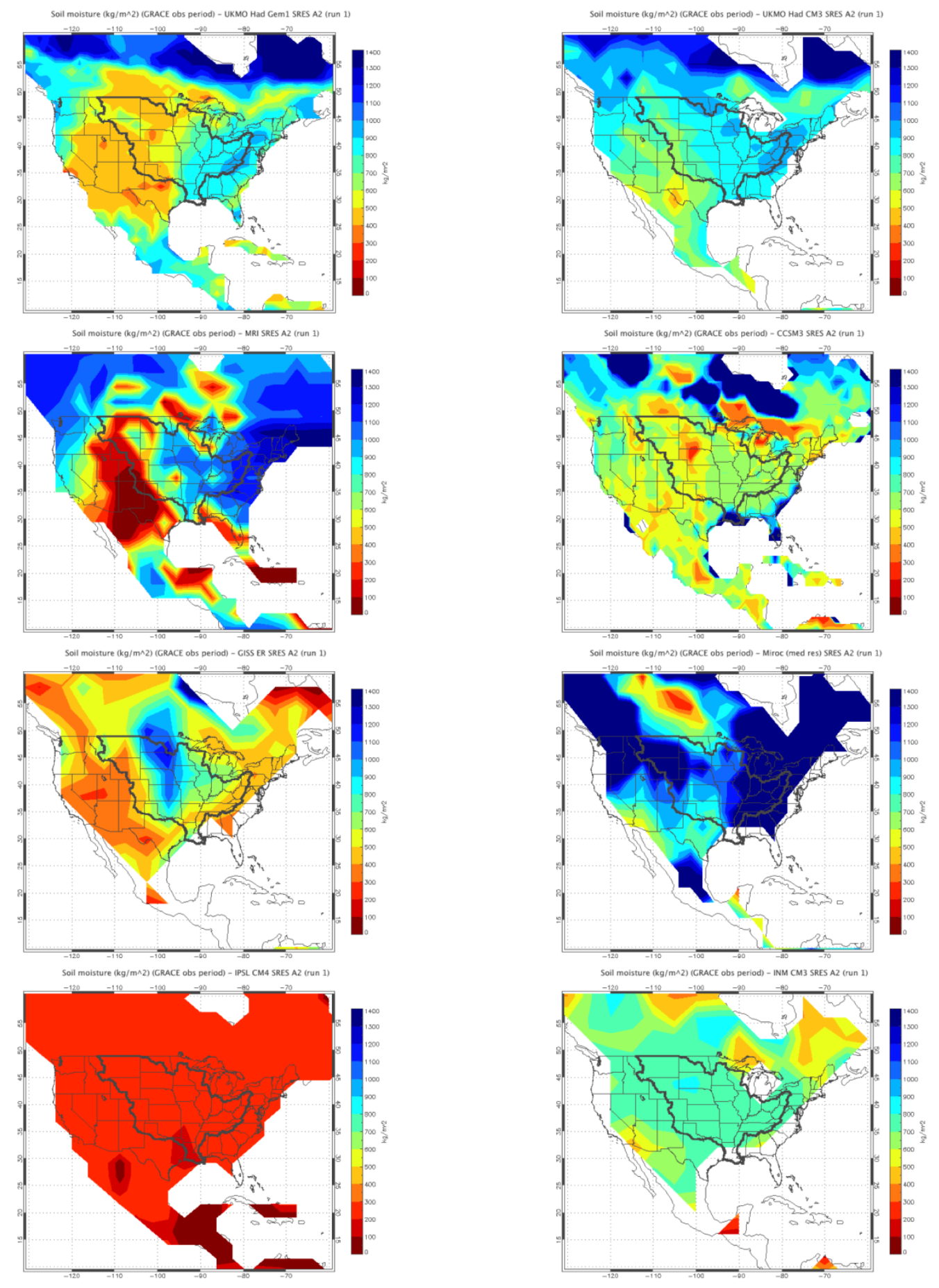

Fig. 7. Same as Fig. 6 but extended to all models analyzed in this thesis. Models from top of first column: HadGEM1, MRI, GISS, IPSL, HadCM3, CCSM3, MIROC, INM CM3. Scale is from 0 to $1400 \mathrm{~kg} \mathrm{~m}^{-2}$. 
NCEP Narth American Regianal Reanalyais

Soil Moisture Content ( $\left.\mathrm{kg} / \mathrm{m}^{\wedge} 2\right)$ Compasite Wean

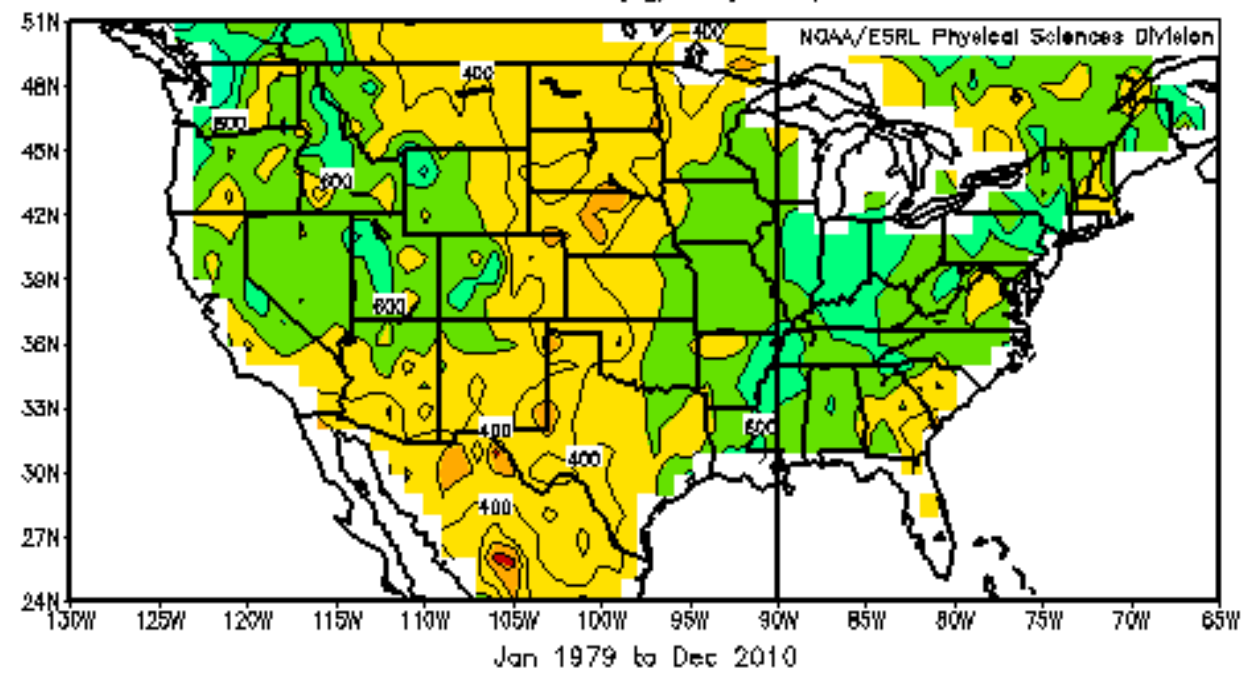

a)

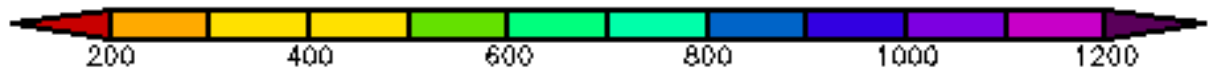

.
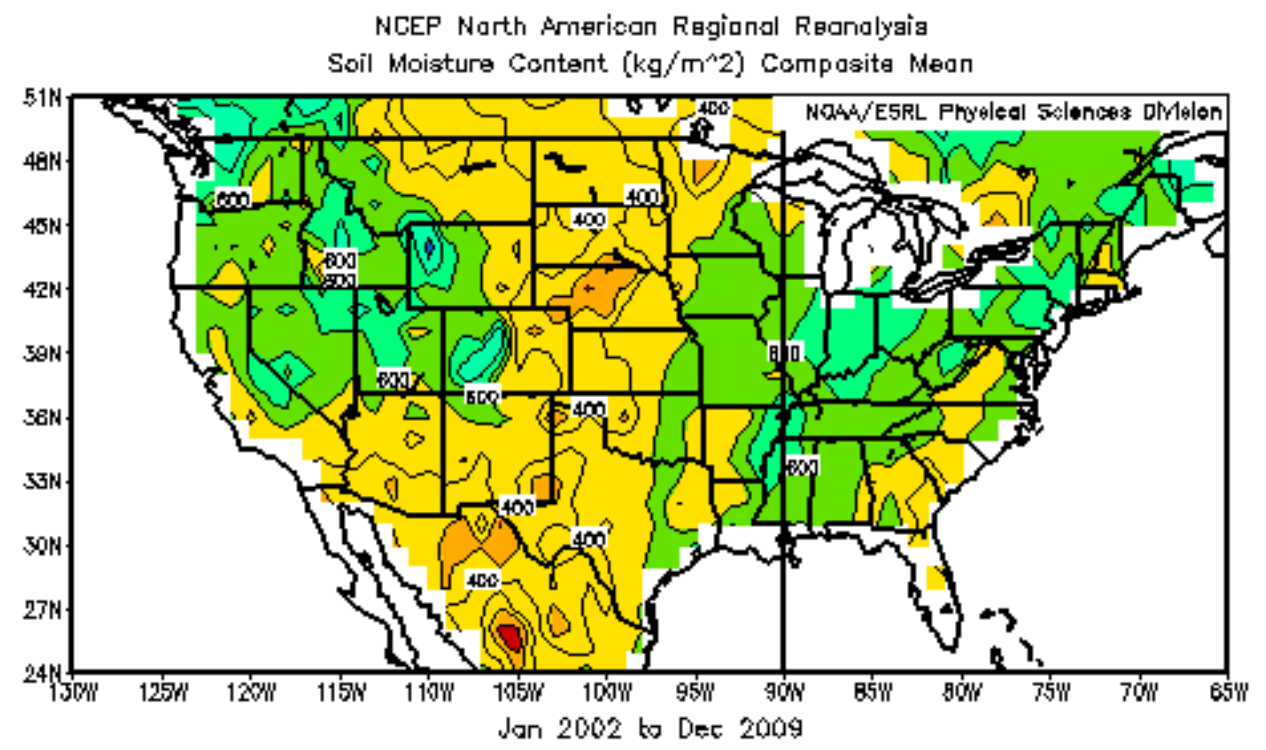

b)

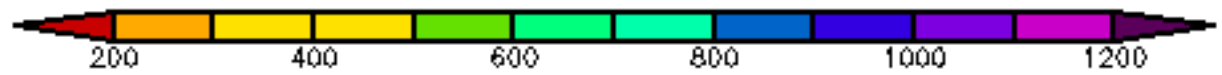

Fig. 8. Top (a): NARR monthly SM averaged from 1979 to 2010. Bottom (b): NARR monthly SM averaged from 2002 to 2009 . Scale is from 200 to $1200 \mathrm{~kg} \mathrm{~m}^{-2}$. 
The IPCC models with distributions most similar to the NARR spatial distributions are the HadGEM1, CCSM3, and MRI, although MRI has a larger range of high-to-low values. CCSM3 also has a northwest to southeast gradient in simulated SM values, with low values ranging from about $200-300 \mathrm{~kg} \mathrm{~m}^{-2}$ in the northwest to high values of about $700-800 \mathrm{~kg} \mathrm{~m}^{-2}$ in the southeast. Although the CCSM3 values and distributions are closest to those of NARR, this model did not perform well in the comparisons with the GRACE annual composite, as discussed above. The CCSM3 simulated annual amplitude of the composite anomaly SM field (dashed teal line in Fig. 4) was underestimated, with low seasonal amplitude and a poor correlation value reflecting the poorly-simulated phase of the annual cycle.

In contrast to the wide range of SM distributions in the eight IPCC models, the spatial distributions of P (Figs. 9 and 10), E (Figs. 11 and 12), and (P-E) (Figs. 13 and 14) are broadly similar among most models. All models show lower values of each of these variables in the west and northwest regions of the MSRB, and higher values in the southeast region of the basin. The monthly-averaged $\mathrm{P}$ values range from lows of 25-50 $\mathrm{mm}$ in the west-northwest to highs in the southeast of about 100-125 mm (Figs. 9 and 10). The exception to this spatial distribution is in the INM CM3 model, which has the lowest $\mathrm{P}$ values in the central and western parts of the MSRB. 
Precipitation (mm/month) (GRACE obs period) - UKMO HadGem1 SRES A2 (run 1)

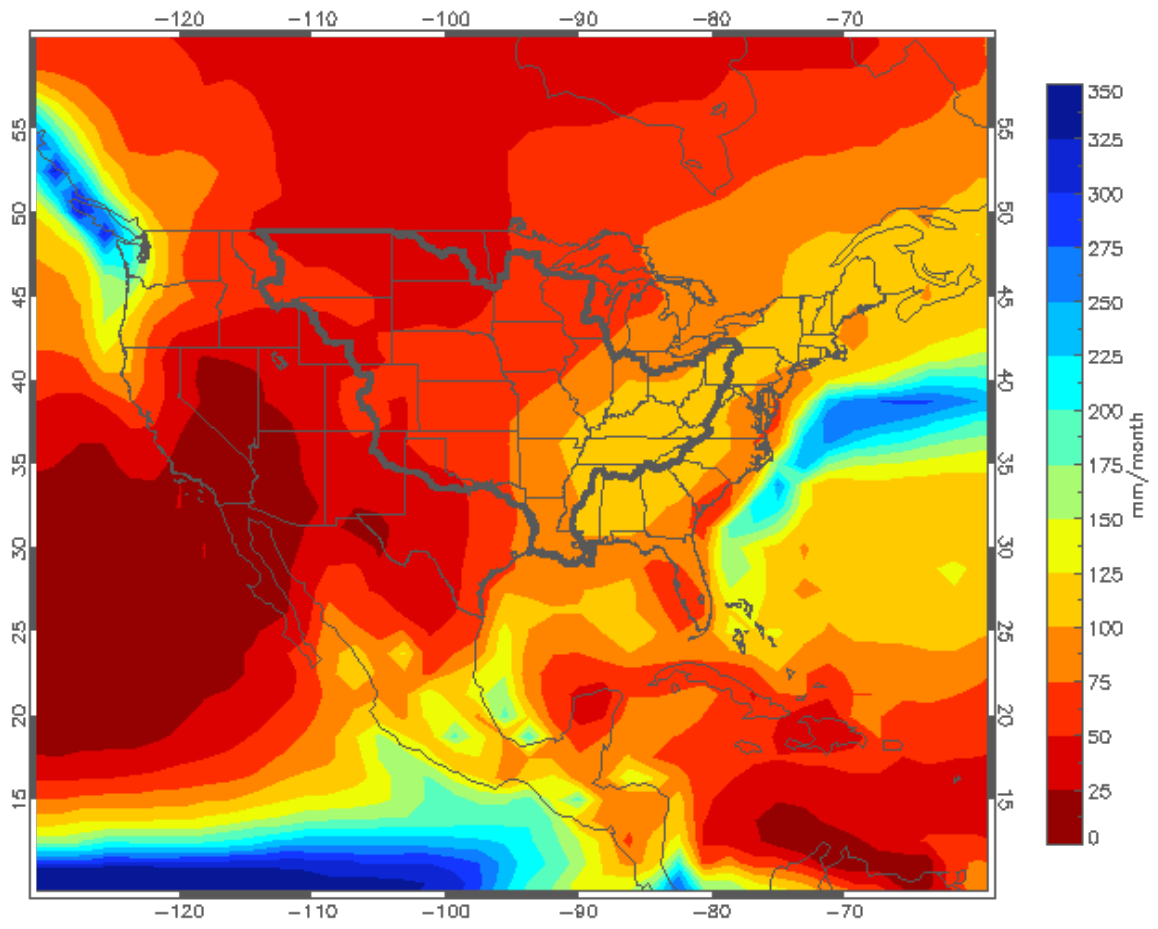

Precipitation (mm/month) (GRACE obs period) - MRI SRES A2 (run 1)

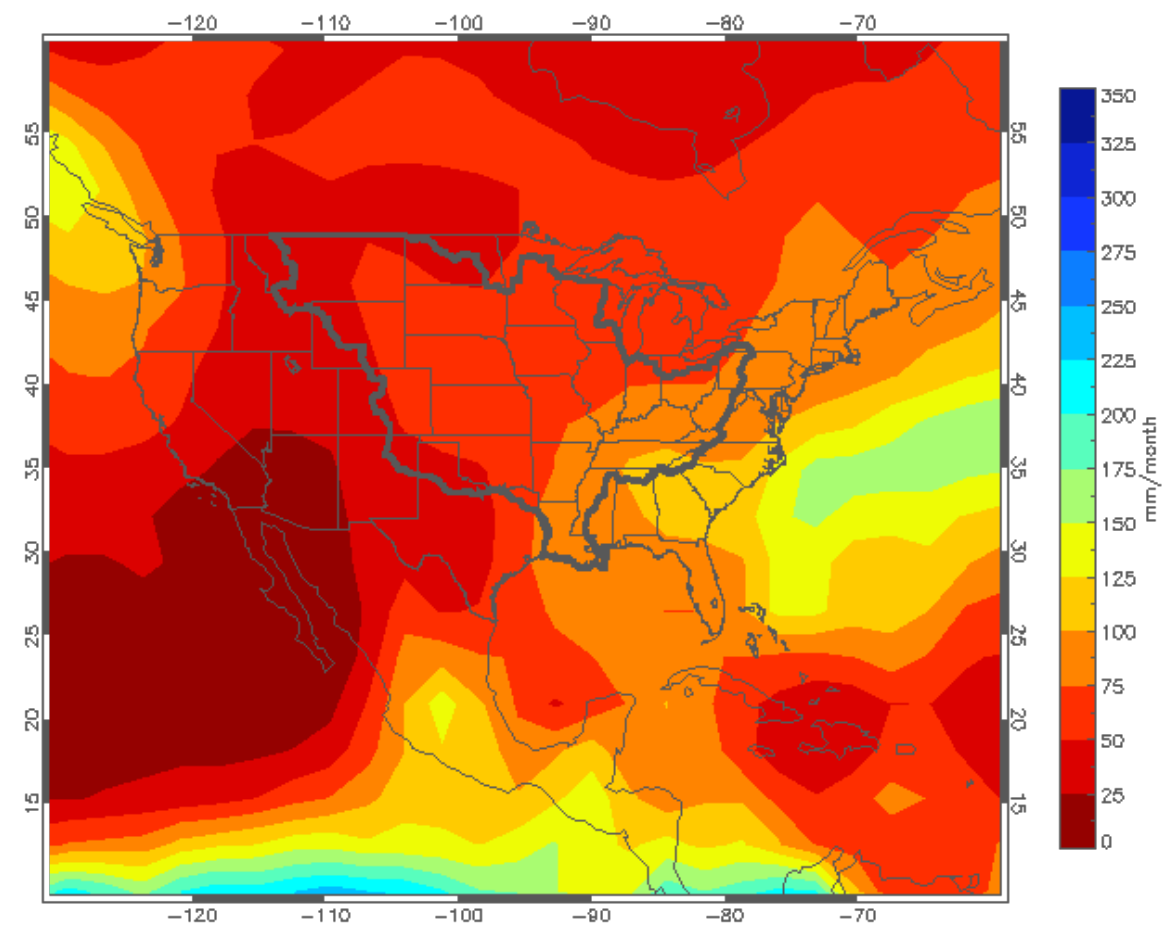

Fig. 9. Spatial distribution of monthly P simulated by HadGEM1 (top) and MRI (bottom) models averaged over GRACE observational period. Scale is from 0 to $350 \mathrm{~mm}$. 

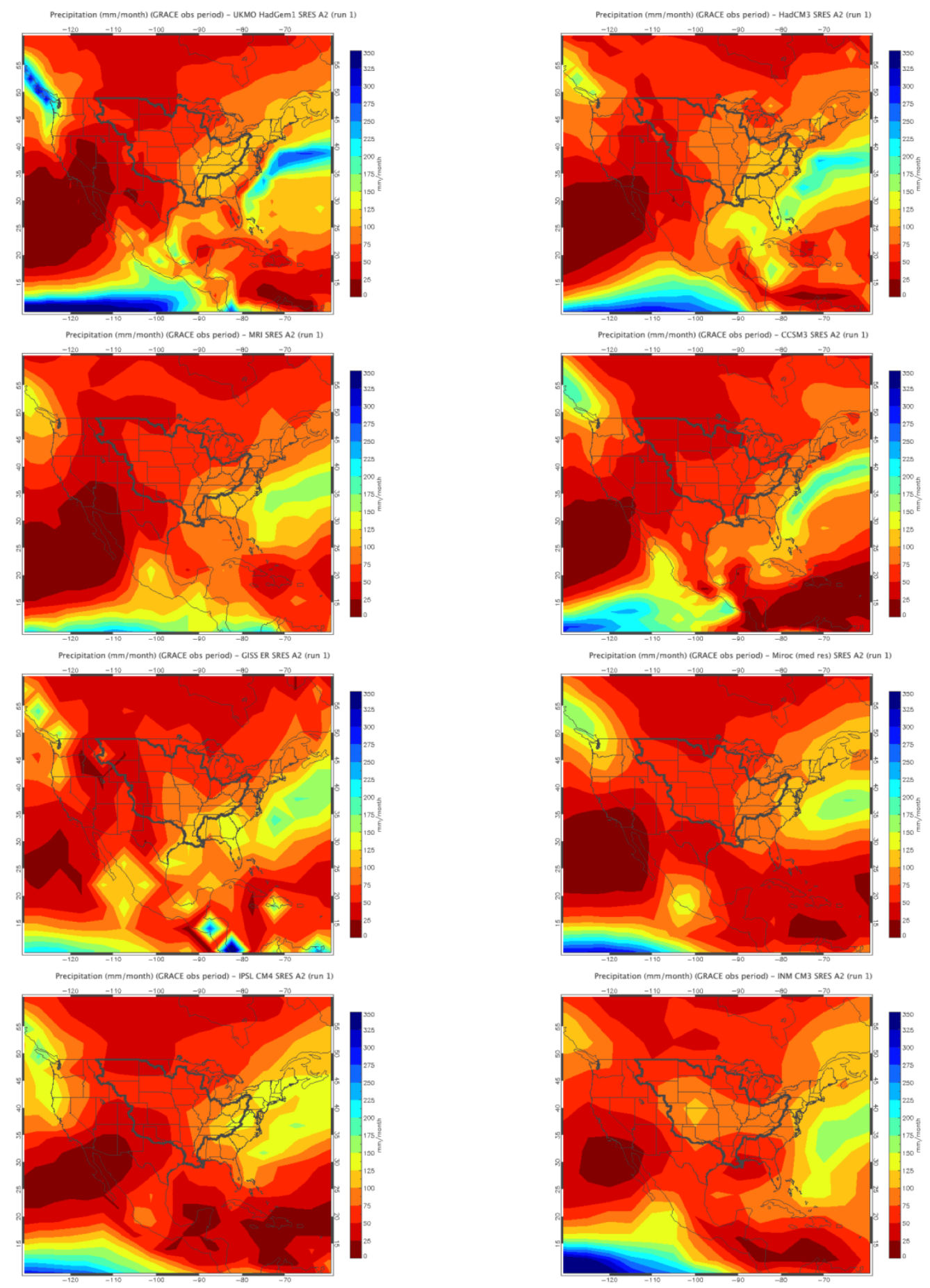

Fig. 10. Same as Fig. 9 but extended to all models analyzed in this thesis. Models from top of first column: HadGEM1, MRI, GISS, IPSL, HadCM3, CCSM3, MIROC, INM CM3. Scale is from 0 to $350 \mathrm{~mm}$. 
The monthly-averaged values of E (Figs. 11 and 12) also show a general northwest to southeast gradient, with low values of about $25-50 \mathrm{~kg} \mathrm{~m}^{-2}$ in the northwest, and high values of about $75-100 \mathrm{~kg} \mathrm{~m}^{-2}$ in the southeast. However, the CCSM3, IPSL, and INM CM3 have smaller ranges of E, with little spatial variation within the MSRB as compared to the other models analyzed here.

Most of the (P-E) monthly-averaged values (Figs. 13 and 14) likewise show a broad northwest to southeast gradient, with low values of about 0 to $-5 \mathrm{~mm}$ in the northwest and high values over $35 \mathrm{~mm}$ in the southeast. Negative values indicate more evaporation than precipitation (drier), whereas positive values mean more precipitation than evaporation (wetter). The exception to this northwest to southeast gradient pattern is the INM CM3 model, which shows overall wetness across the MSRB. Also, the IPSL model fails to capture the dryness of the northwest region.

$\mathrm{P}$ and $\mathrm{E}$ are significant contributors to SM, both in the model and in reality. However, as we have shown, SM distributions are substantially different from model to model while $\mathrm{P}, \mathrm{E}$, and (P-E) distributions are broadly similar. This may be due in part to the definition of the specific IPCC output variable being analyzed here. We have analyzed the soil moisture content - which, as stated before, sums the water present in all layers of the soil model, and averages it over the land area of each grid cell (Meehl et al. 2007b). This was used as the IPCC output variable best suited to compare directly to observations of TWS. However, each land model has a different number of layers for heat and water transfer, as well as a different total depth. This makes the direct comparison of this variable between each model somewhat difficult. 


\section{Evaporation flux (kg/m^2/month) (GRACE obs period) - Had Gem1 SRES A2 (run 1)}

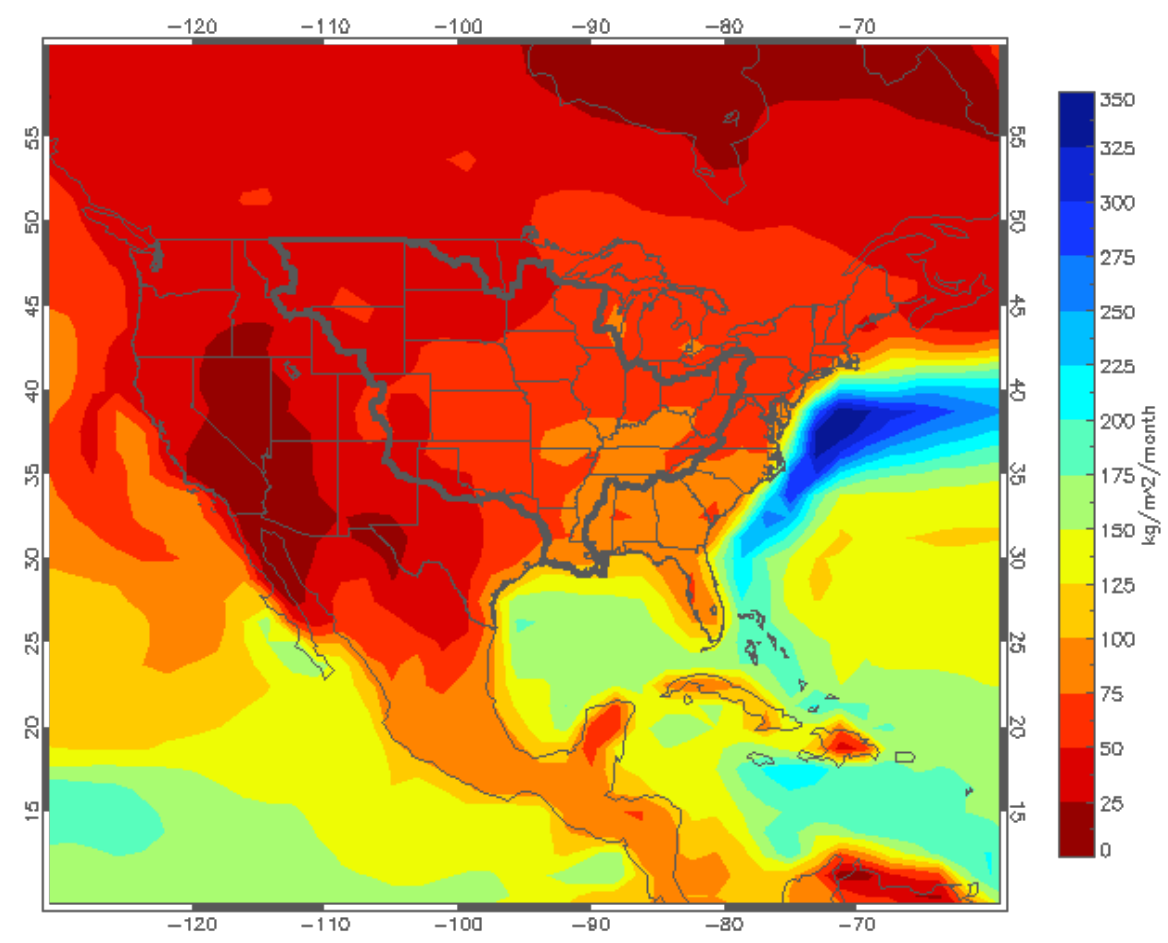

Evaporation flux (kg/mA2/month) (GRACE obs period) - MRI SRES A2 (run 1)

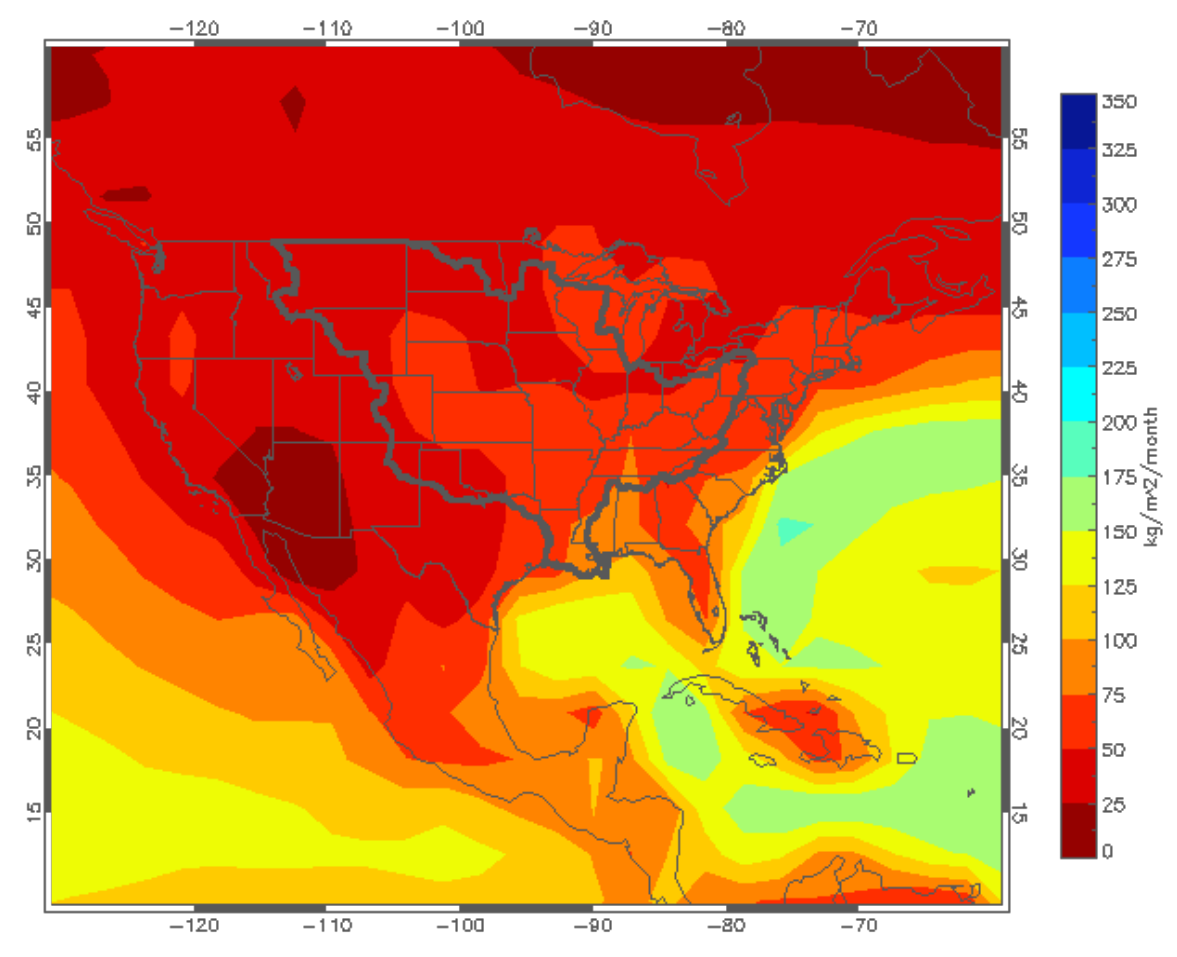

Fig. 11. Spatial distribution of monthly E simulated by HadGEM1 (top) and MRI (bottom) models averaged over GRACE obs period. Scale is from 0 to $350 \mathrm{~kg} \mathrm{~m}^{-2}$. 

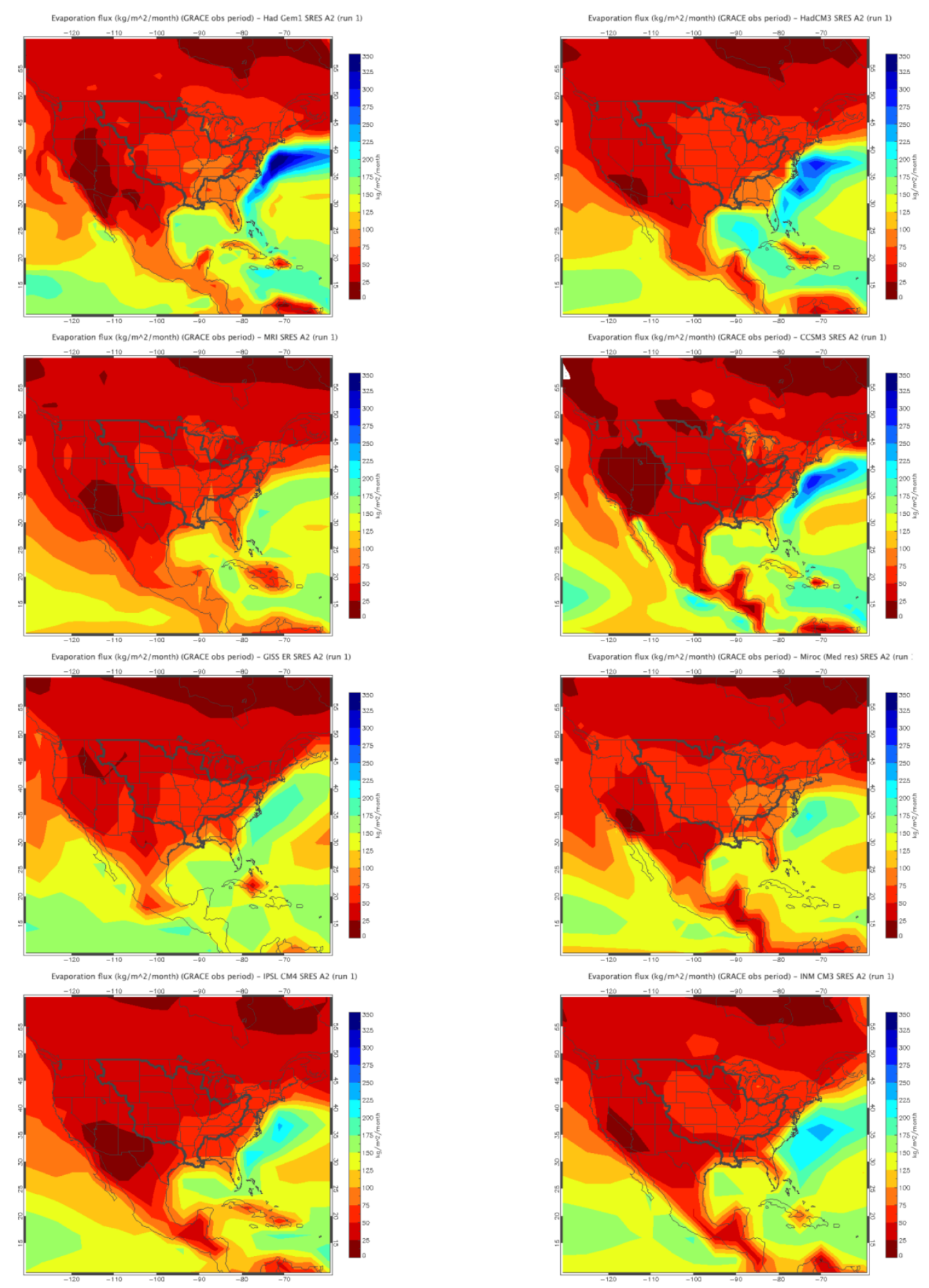

Fig. 12. Same as Fig. 11 but extended to all models analyzed in this thesis. Models from top of first column: HadGEM1, MRI, GISS, IPSL, HadCM3, CCSM3, MIROC, INM CM3. Scale is from 0 to $350 \mathrm{~kg} \mathrm{~m}^{-2}$. 


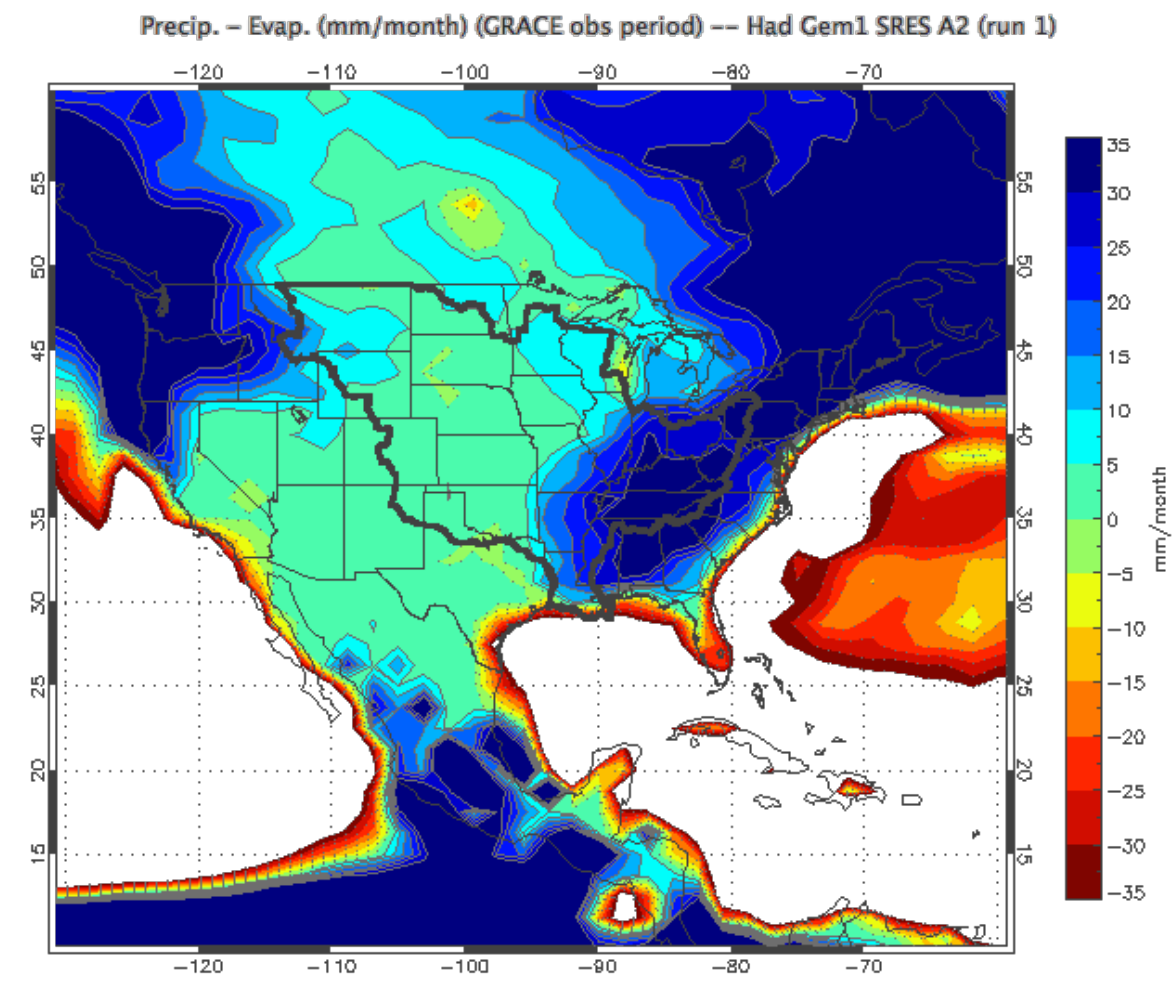

Precip. - Evap. (mm/month) (GRACE obs period) -- MRI SRES A2 (run 1)

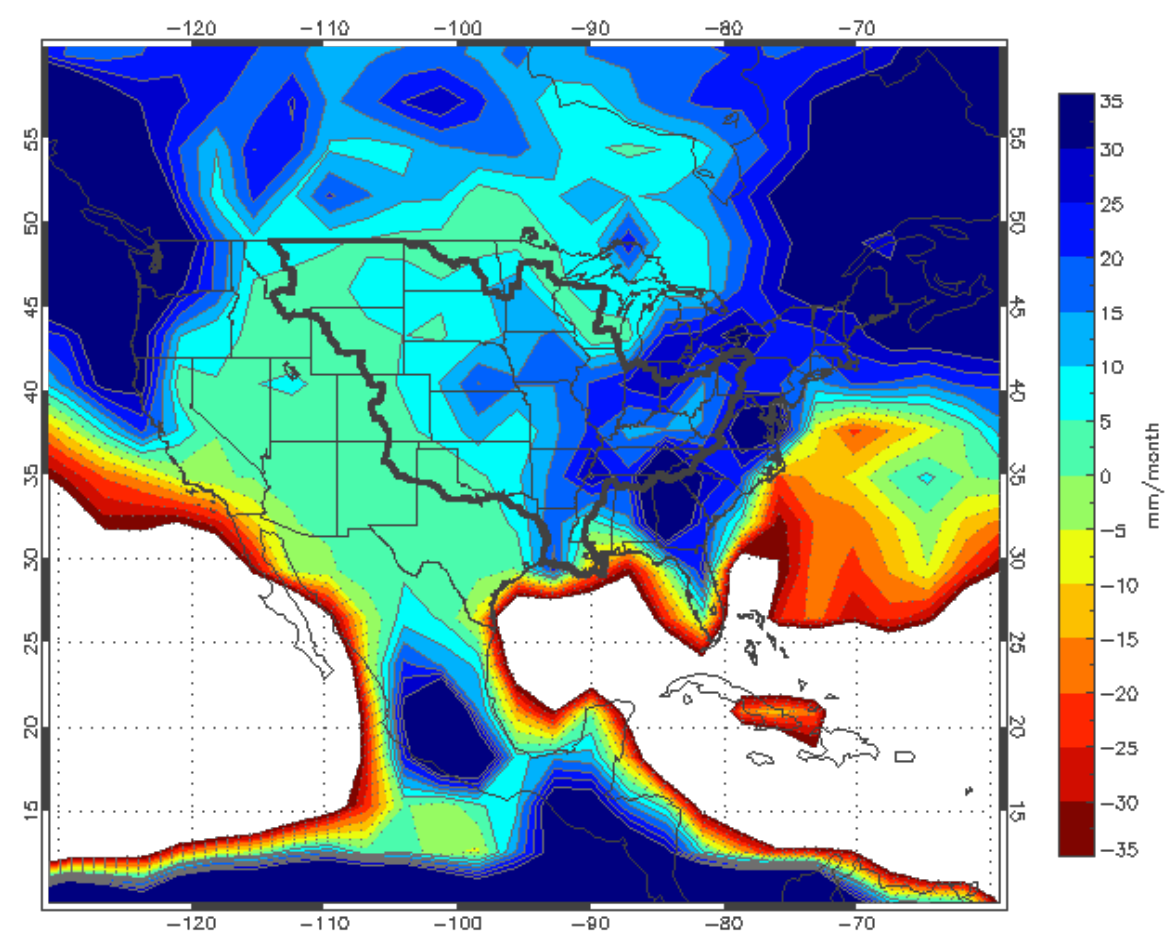

Fig. 13. Spatial distribution of monthly (P-E) simulated by HadGEM1 (top) and MRI (bottom) models averaged over GRACE obs period. Scale is from -35 to $35 \mathrm{~mm}$. 

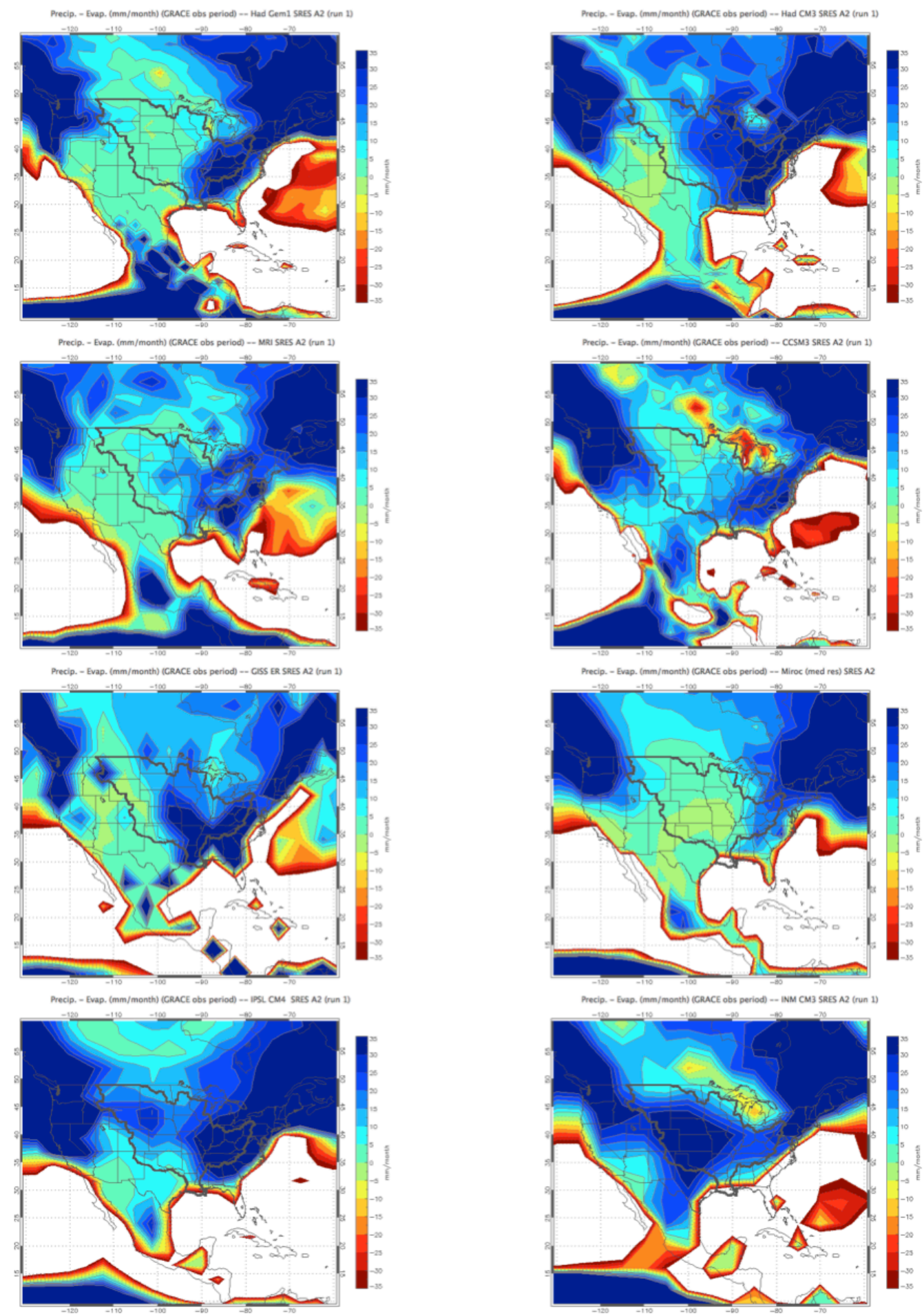

Fig. 14. Same as Fig. 13 but extended to all models analyzed in this thesis. Models from top of first column: HadGEM1, MRI, GISS, IPSL, HadCM3, CCSM3, MIROC, INM CM3. Scale is from -35 to $35 \mathrm{~mm}$. 
To determine if there is still significant variability among the models' simulated SM down to a specified depth, the IPCC output field moisture content of soil layer (SM0.1) was also analyzed for each model (except for the IPSL model which did not have this variable archived for the A2 scenario run in the CMIP3 database). The SM0.1 output field sums the water present in the top $0.1 \mathrm{~m}$ of the soil model and averages it over the land area of each grid cell (Meehl et al. 2007b); it is defined the same as the soil moisture content (SM) but for the upper $0.1 \mathrm{~m}$ of the ground only.

Figure 15 shows the spatial distributions of the monthly SM0.1 averaged over the GRACE observational period for seven of the eight models analyzed in this thesis. Just as with the SM, there is still a wide range of simulated results, although not quite as diverse as the simulated SM fields. Again, this result shows that the soil moisture in general is not simulated consistently (and therefore not simulated well) across the IPCC suite, even for just the top $10 \mathrm{~cm}(0.1 \mathrm{~m})$ layer.

In an attempt to better determine the cause of the vastly different SM distributions among the models, the IPCC output field of runoff flux (R), which is the total runoff including drainage, is examined for select IPCC models. The models for which we examine R are HadGEM1, MRI, IPSL, and MIROC, which are the two models that best reproduce the MSRB SM distribution (HadGEM1 and MRI), and the driest (IPSL) and the moistest (MIROC) models with respect to this comparison. $R$ is the sum of $R_{s}$ and $R_{g}$ in Eq. (2). 

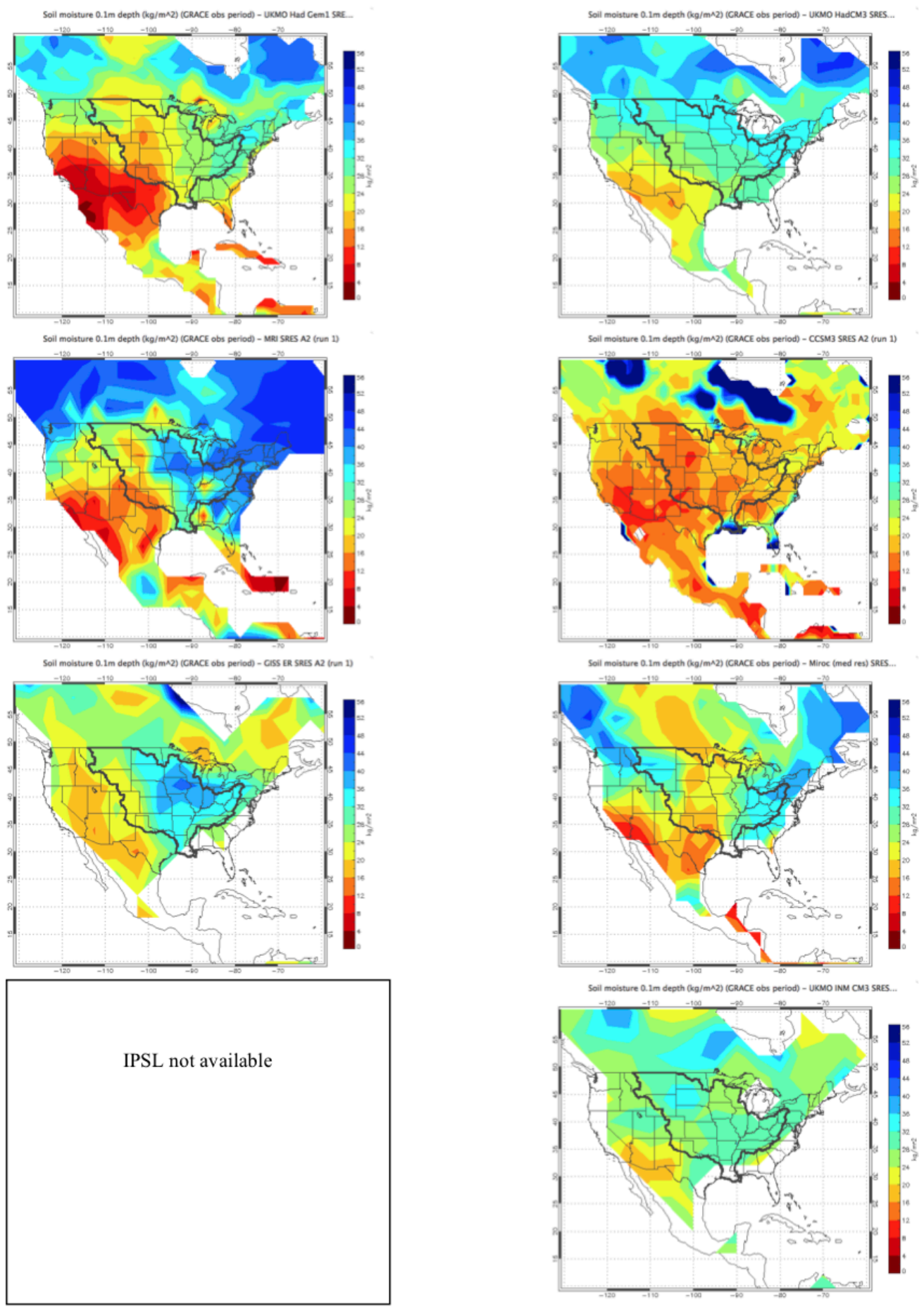

Fig. 15. Spatial distribution of monthly SM within upper 0.1 meters as simulated by seven of the eight models analyzed in this thesis and averaged over the GRACE observational period. Models from top of first column: HadGEM1, MRI, GISS, (IPSL not available), HadCM3, CCSM3, MIROC, INM CM3. Scale is from 0 to $56 \mathrm{~kg} \mathrm{~m}^{-2}$. 
Table 7 displays for each of the above four models the average values of SM, P, E, and R within the MSRB over the GRACE observational period. As shown, all models produce practically identical values of P. HadGEM1 and MRI, the two most accurate models, additionally produce practically the same amount of $\mathrm{E}$ and $\mathrm{R}$.

The IPSL model, however, which has the lowest average SM of all the models, produces runoff twice as high as that projected by HadGEM1 and MRI. Since runoff is a sink term in the moisture budget equation, this appears to explain the lower SM projected by this model compared to HadGEM1 and MRI. Accordingly, IPSL produces less E than HadGEM1 and MRI, as there is less moisture in the land available for evaporation.

In contrast, the MIROC model, which projects the highest average SM of all the models, produces runoff over twice as low compared to HadGEM1 and MRI. This appears to explain the higher SM in this model compared to HadGEM1 and MRI. Accordingly, MIROC produces more E than HadGEM1 and MRI, as there is more moisture in the land available for evaporation.

Table 7. Average values of SM, P, E, and R for the MSRB over the GRACE observational period for HadGEM1, MRI, IPSL, and MIROC.

\begin{tabular}{ccccc}
\hline \hline Model & SM $\left.\mathbf{~ k g ~ m}^{-2}\right)$ & $\mathbf{P}(\mathbf{m m})$ & $\mathbf{E} \mathbf{~ ( k g ~ m}^{-2}$ & $\mathbf{R ~ ( m m )}$ \\
\hline UKMO HadGEM1 & 625.70 & 68.56 & 57.92 & 13.03 \\
MRI-CGCM2.3.2 & 714.81 & 65.52 & 53.81 & 13.10 \\
IPSL-CM4 & 270.42 & 65.48 & 40.72 & 26.76 \\
MIROC3.2-medres & 1215.82 & 65.76 & 63.16 & 5.85 \\
\hline
\end{tabular}

It thus seems clear after examining the average runoff values over the MSRB for the GRACE observational period that runoff is the controlling sink term that counters $\mathrm{P}$ in determining TWS amounts produced by the IPCC GCMs. With the same amount of 
water being input into each land model via $\mathrm{P}$, high runoff leads to less SM, and less moisture available for E. And vice versa, low runoff leads to more SM, and more moisture available for E. This explains why MIROC, which projects the highest E, has the highest SM, and why IPSL, which projects the lowest E, has the lowest SM.

In conclusion, although we have shown substantial model-to-model variations in simulated SM distributions and annual cycles, we have been able to identify two models (HadGEM1 and MRI) that appear to do a reasonable job at reproducing SM values over the GRACE observational period and over the MSRB. The distributed SM from the HadGEM1 model matches NARR observations quite well, and has a 0.99 correlation value to the GRACE annual composite. We feel confident in continued analysis of these models to now examine the changes in SM distributions simulated over the $21^{\text {st }}$ century.

\section{4. $21^{\text {st }}$ century trends under the A2 scenario}

Having established that SM output from both the HadGEM1 and MRI models compare well to GRACE observations, we now extend our analyses to cover the years 2000-2100 under the A2 scenario. Our goal here is to examine potential changes in areaaveraged SM over the MSRB over the next century as the climate warms.

\section{a. Soil moisture}

SM trends for the HadGEM1 and MRI models were calculated for the entire $21^{\text {st }}$ century under the A2 scenario and tested for significance at the $95 \%$ confidence level, accounting for autocorrelation. Wigley (2006) explains that autocorrelation is used when data points are dependent temporally on the value of the data point before them; the data values are not independent of one another in time. He shows that this dependency 
reduces the actual sample size to an "effective sample size," and this sample size reduction increases the standard error. An increased standard error widens the confidence intervals, making the trend calculations less likely to reach significance, as compared to trends calculated without autocorrelation (Wigley 2006).

This statistical analysis in this thesis was done by first extracting and averaging the IPCC SM monthly data from within the MSRB, and then averaging the MSRB monthly data over each year for the $21^{\text {st }}$ century. The annually-averaged data was plotted in a time series and a linear trend was fitted for each model. The annually-averaged SM time series and trend lines for the top two models are shown below in Fig. 16.

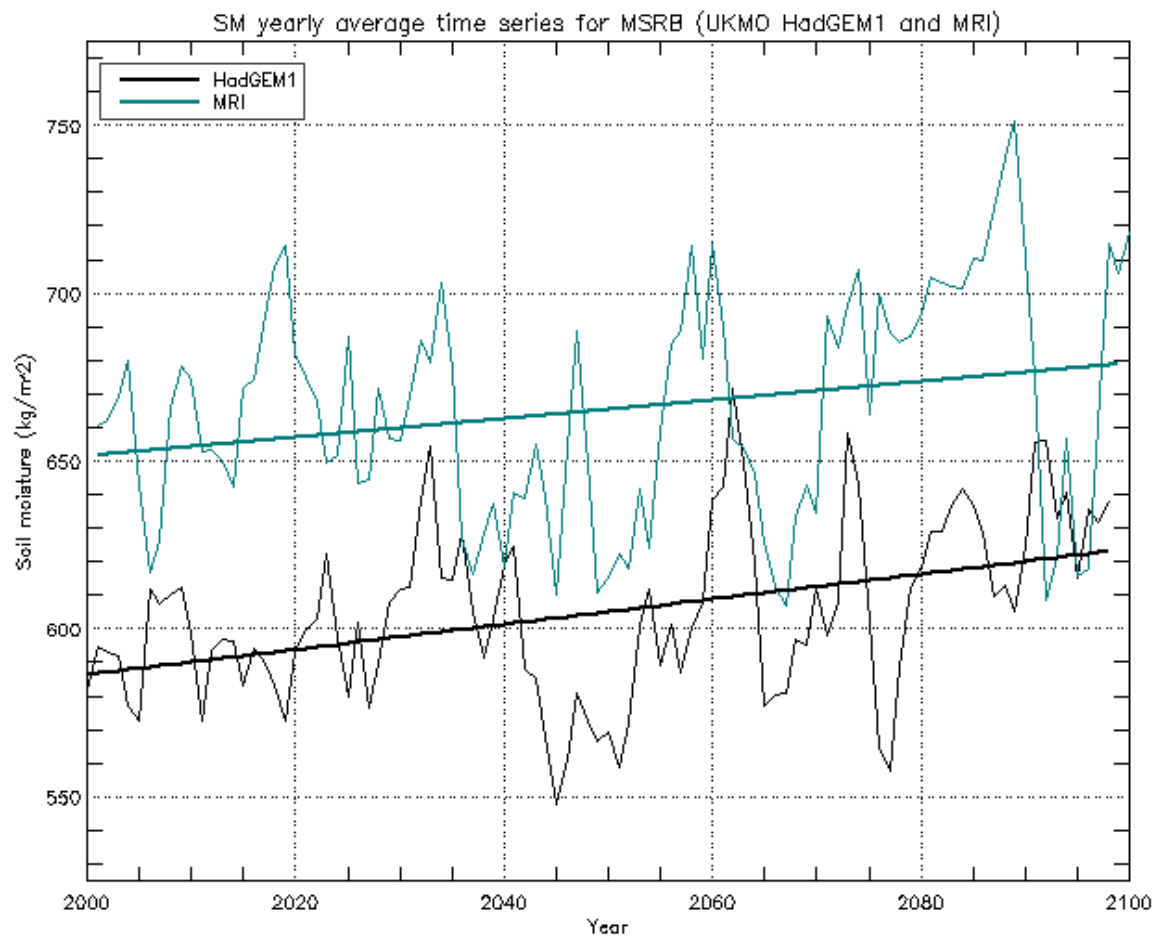

Fig. 16. Time series of annual average SM in the MSRB with trend lines for HadGEM1 (black) and MRI (teal) over the $21^{\text {st }}$ century for the A2 scenario. 
The HadGEM1 simulation for the $21^{\text {st }}$ century (black line in Fig. 16) shows an upward trend of SM over the MSRB with an increase of $3.74 \pm 3.34 \mathrm{~kg} \mathrm{~m}^{-2}$ decade $^{-1}$. This result is significant at the $90 \%$ confidence level but not the $95 \%$ level. The annually-averaged SM across the MSRB over the last decade of the $21^{\text {st }}$ century minus that over the first decade has the value $44.77 \pm 10.65 \mathrm{~kg} \mathrm{~m}^{-2}$. This is significant at the 95\% confidence level and reinforces the finding that SM in the HadGEM1 model increases across the MSRB during the $21^{\text {st }}$ century. The decadal difference plot (Fig. 17), which shows the "last minus first" decadally-averaged SM distribution change, indicates that by the last decade of the $21^{\text {st }}$ century there is a widespread increase in SM in the central part of the MSRB up through the western Great Lakes region, with slight decreases in the northern plains and the southeastern portions of the MSRB. 


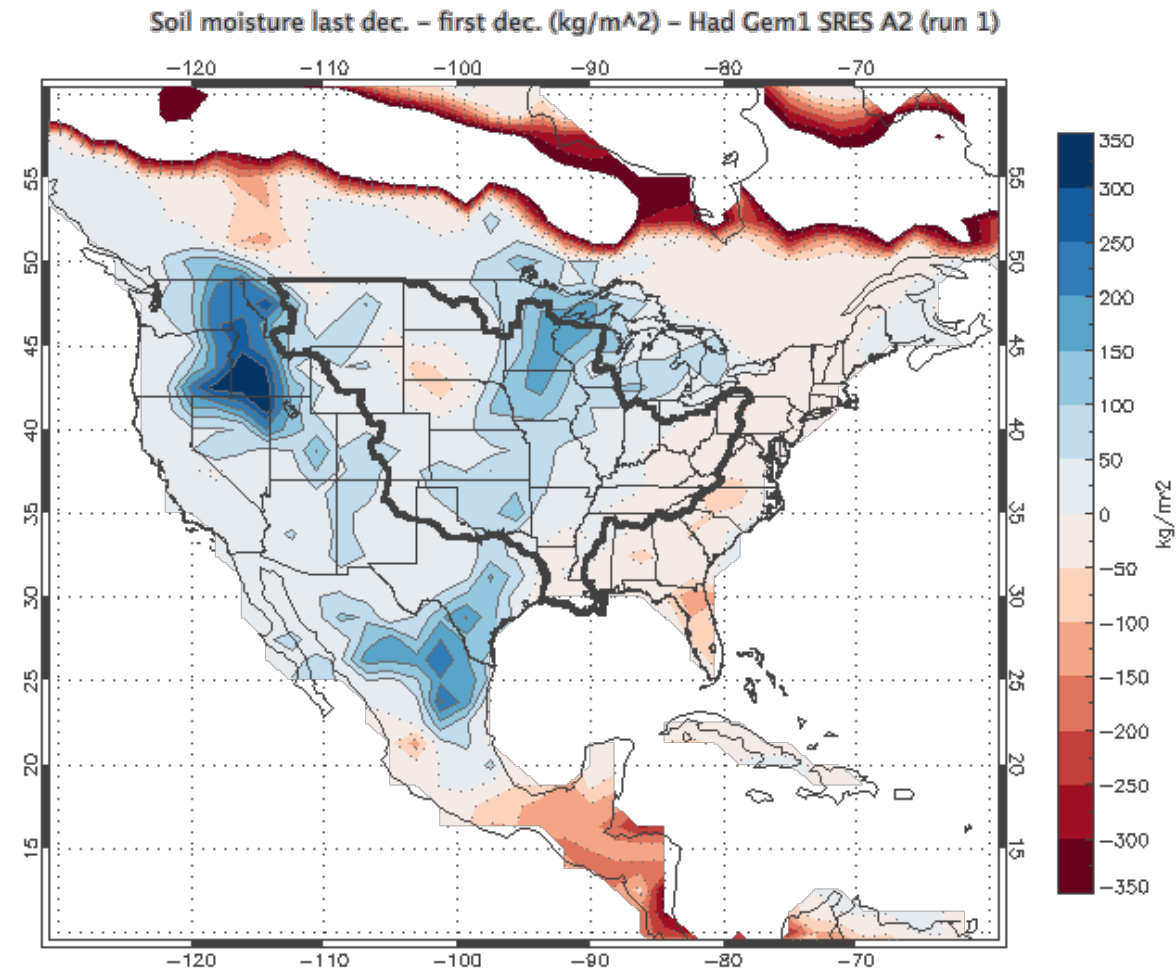

Fig. 17. Difference plot of SM for HadGEM1 showing the last decade of the $21^{\text {st }}$ century minus the first decade. Blue areas indicate a moistening trend, while red areas with dotted contour lines indicate a drying trend. Scale is from -350 to $350 \mathrm{~kg} \mathrm{~m}^{-2}$.

The MRI model's $21^{\text {st }}$ century SM trend (teal line in Fig. 16) is also calculated to be upward at $2.78 \pm 5.97 \mathrm{~kg} \mathrm{~m}^{-2}$ decade $^{-1}$, although this fails the significance tests at both the $95 \%$ and $90 \%$ confidence levels. The annually-averaged SM across the MSRB over the last decade of the $21^{\text {st }}$ century minus that over the first decade has the value of $2.33 \pm$ $13.33 \mathrm{~kg} \mathrm{~m}^{-2}$, which is also not significant at the $95 \%$ and $90 \%$ confidence levels. This is most likely due to the large decline in simulated SM values at the end of the century, as shown in Fig. 16. Spatially, the decadal difference plot (Fig. 18) shows that there is a widespread decrease in simulated SM values by the end of the century, with large increases noted in the northern plains and Rockies regions. This wide range of high 
positive and negative SM change values across the MSRB may be a contributing factor to the high variability in the SM time series (Fig. 16), causing uncertainty in the trend analysis (e.g., lack of statistical confidence).

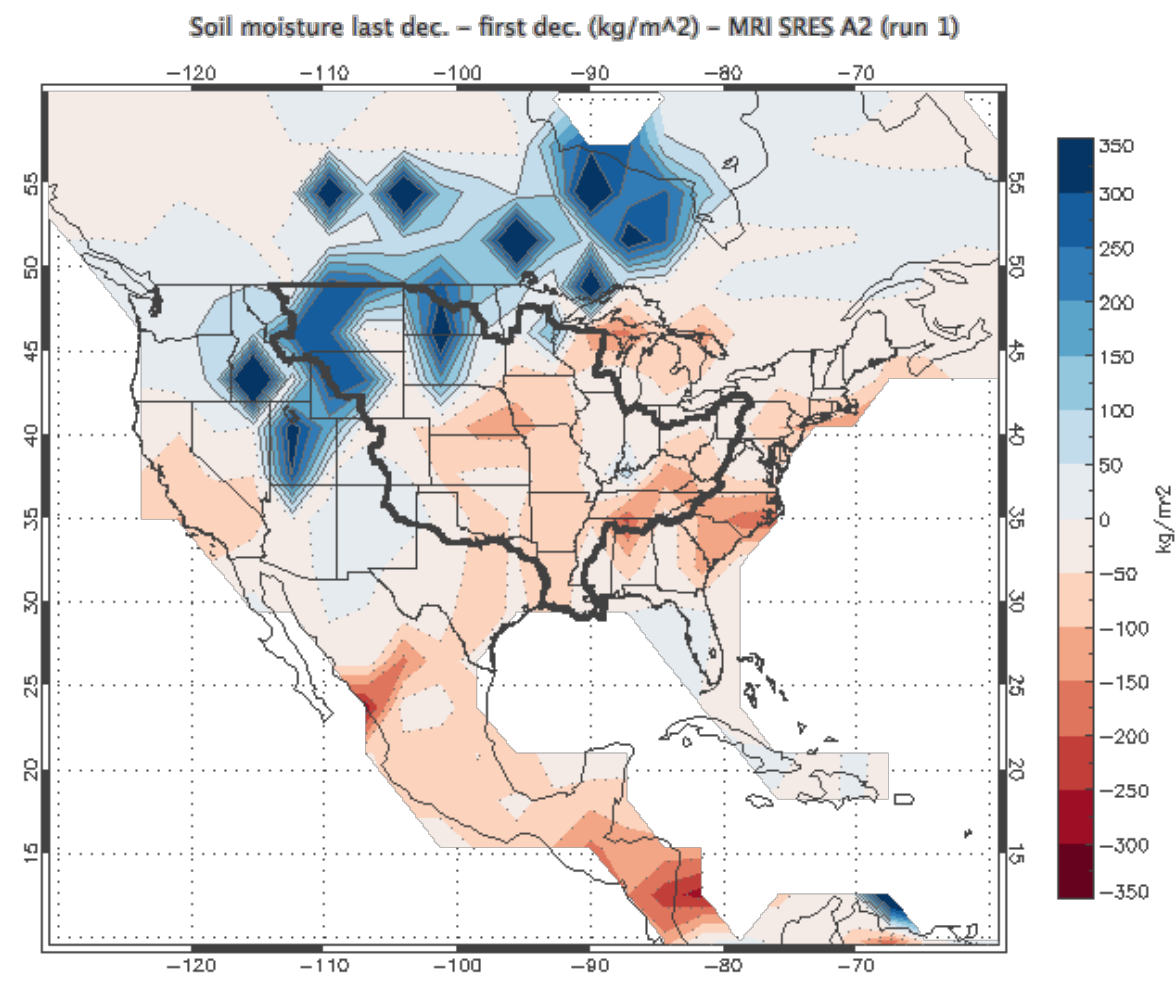

Fig. 18. Difference plot of SM for MRI showing the last decade of the $21^{\text {st }}$ century minus the first decade. Blue areas indicate a moistening trend, while red areas with dotted contour lines indicate a drying trend. Scale is from -350 to $350 \mathrm{~kg} \mathrm{~m}^{-2}$.

A summary of the HadGEM1 and MRI SM trend results presented above is shown in Table 8, along with the $21^{\text {st }}$ century trends in MSRB-averaged SM from the other models analyzed in this thesis. Trends are given in $\mathrm{kg} \mathrm{m}^{-2}$ decade $^{-1}$, and bolded text indicates statistical significance at the $95 \%$ confidence level, accounting for autocorrelation. The majority of the significant trends show a decrease in SM across the 
MSRB over the $21^{\text {st }}$ century under the A2 scenario. However, these results are from the models that did not fare well in our comparisons to the GRACE observations, as was discussed in Section 3. HadGEM1 and MRI both show upward SM trends, but only HadGEM1 has a significant $21^{\text {st }}$ century SM trend at the $90 \%$ confidence level, and a "last minus first" decadal difference significant at the $95 \%$ confidence level. Since HadGEM1 has a 0.99 correlation to the GRACE composite (Table 2), the smallest area difference from the GRACE composite (Table 3), one of the lowest amplitude differences from the GRACE composite (Table 4), and has a similar spatial resolution to NARR, we believe that HadGEM1 is valid to use for analyzing SM in the MSRB.

Table 8. From left to right: model name; model correlation with GRACE (from Section 3); SM trend from 2000-2100 with uncertainty calculated at the 95\% confidence level (bolded indicates significance); the mean difference of projected SM between the last decade and the first decade of the $21^{\text {st }}$ century with uncertainty calculated at the $95 \%$ confidence level (bolded indicates significance). Arranged by most positive trend at top.

\begin{tabular}{cccccc}
\hline Model & GRACE $\mathbf{r}$ & Trend* & Uncert.* & Mean Diff.** & Uncert.** \\
\hline UKMO-HadGEM1 & 0.994 & 3.74 & 4.06 & $\mathbf{4 4 . 7 7}$ & $\mathbf{1 0 . 6 5}$ \\
MRI-CGCM2.3.2 & 0.950 & 2.78 & 5.97 & 2.33 & 13.33 \\
CCSM3 & 0.882 & $\mathbf{0 . 3 8 7}$ & $\mathbf{0 . 2 9}$ & 2.67 & 3.63 \\
UKMO-HadCM3 & 0.900 & -0.39 & 2.23 & -6.83 & 14.08 \\
GISS-ER & 0.896 & $\mathbf{- 1 . 5 4}$ & $\mathbf{1 . 3 6}$ & -4.39 & 4.92 \\
INM-CM3.0 & 0.966 & $\mathbf{- 1 . 7 2}$ & $\mathbf{0 . 6 5 8}$ & -12.63 & 12.73 \\
IPSL-CM4 & 0.832 & $\mathbf{- 1 . 9 6}$ & $\mathbf{0 . 6 9 5}$ & $\mathbf{- 2 0 . 4 7}$ & $\mathbf{7 . 3 4}$ \\
MIROC3.2-medres & 0.972 & $\mathbf{- 3 1 . 3}$ & $\mathbf{0 . 7 4 9}$ & $\mathbf{- 2 7 2 . 9 7}$ & $\mathbf{1 3 . 8 3}$ \\
\hline
\end{tabular}

* Trend in $\mathrm{kg} \mathrm{m}^{-2}$ decade $^{-1}$

** Mean difference in $\mathrm{kg} \mathrm{m}^{-2}$ 


\section{b. Precipitation and evaporation}

Trends of precipitation (P), evaporation (E), and (P-E) were also analyzed for the HadGEM1 and MRI models. TWS, which changes mainly with SM variability in the MSRB, is approximately the quantity (P-E) (Rodell and Famiglietti 2001; Rodell et al. 2007; Rodell 2008; Music and Caya 2007). These variables could therefore assist in describing and explaining the SM trends discussed above.

The HadGEM1-simulated P field across the MSRB for the $21^{\text {st }}$ century has a downward trend of $-0.54 \pm 0.46 \mathrm{~kg} \mathrm{~m}^{-2}$ decade $^{-1}$, which is significant at the $90 \%$ confidence level, but not significant at the $95 \%$ confidence level. This would be equivalent to seeing area-averaged P reduced across the MSRB by about $5 \mathrm{~mm}$, or 0.2 inches, by the end of the $21^{\text {st }}$ century. Thus, the HadGEM1 model predicts less overall $\mathrm{P}$ over the MSRB. Spatially, there is an overall small decrease in P across the MSRB (Fig. 19, light pink shading) when looking at the difference between the average of the last decade minus the average of the first decade of the $21^{\text {st }}$ century simulation. Across the southeast U.S. the decrease is more pronounced, although this is outside the MSRB. In contrast, the MRI model shows an upward trend in P of $0.51 \pm 0.38 \mathrm{~kg} \mathrm{~m}^{-2}$ decade $^{-1}$, which is significant at the $95 \%$ confidence level. In opposition to HadGEM1, this trend would give an increase in P across the MSRB of about $5 \mathrm{~mm}$, or 0.2 inches, by the end of the $21^{\text {st }}$ century. This increase appears widespread across the MSRB, as shown in Fig. 19 (light blue colors). 

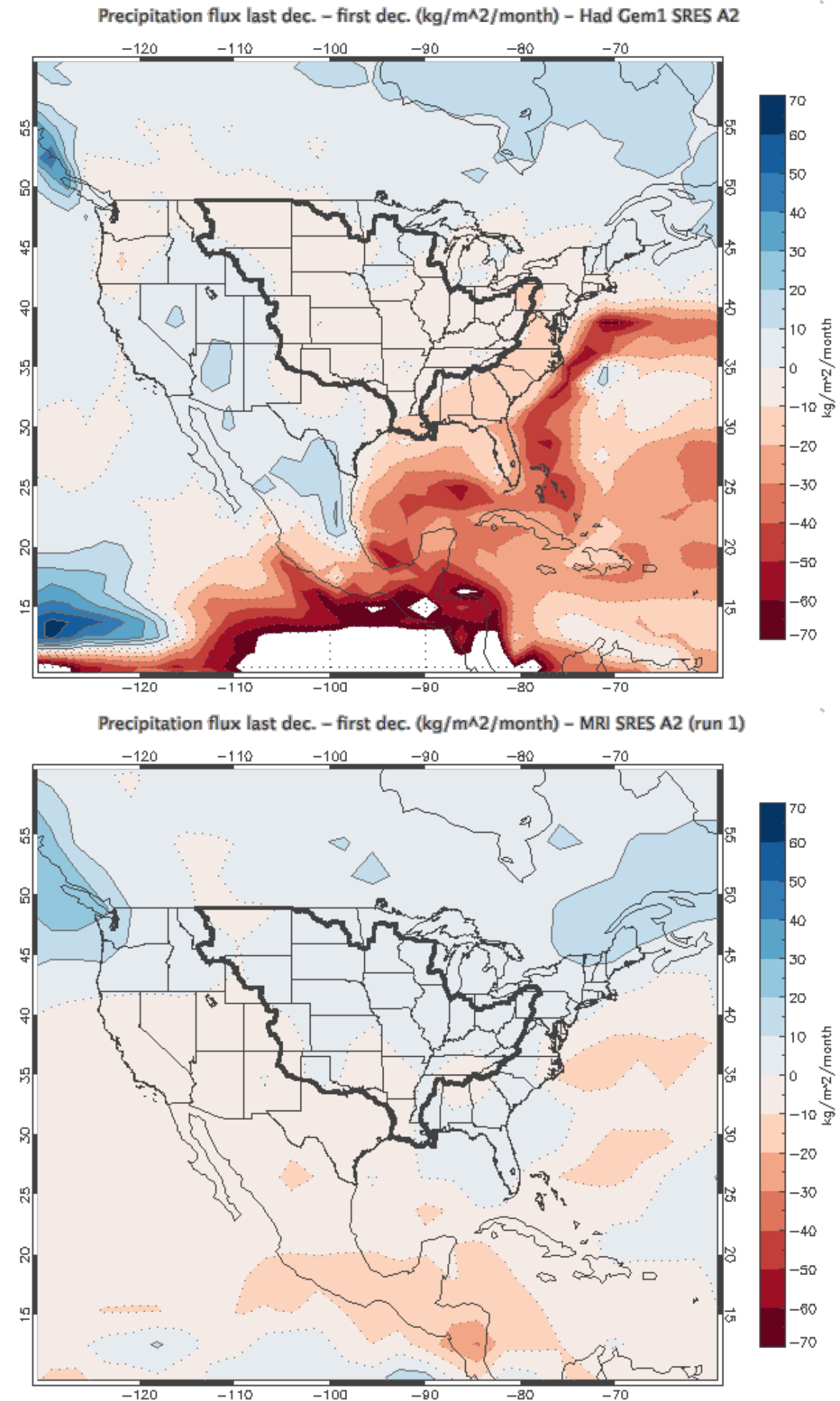

Fig. 19. Difference plot of $P$ for HadGEM1 (top) and MRI (bottom) showing the last decade of the $21^{\text {st }}$ century minus the first decade. Scale is from -70 to $70 \mathrm{~kg} \mathrm{~m}^{-2}$. 
The HadGEM1 trend in evaporation (E) shows a significant reduction over the $21^{\text {st }}$ century at $-0.41 \pm 0.33 \mathrm{~kg} \mathrm{~m}^{-2}$ decade $^{-1}(95 \%$ confidence level $)$. The decrease is noted across most of the MSRB (Fig. 20, light pink shading). As was the case with the $\mathrm{P}$ field, the MRI simulation features values of $E$ increasing by $0.45 \pm 0.14 \mathrm{~kg} \mathrm{~m}^{-2}$ decade $^{-1}$ ( $95 \%$ confidence level). The increase is spread across the MSRB (Fig. 20, light blue shading).

The HadGEM1 model therefore simulates decreasing basin-averaged P and E during the $21^{\text {st }}$ century, whereas the MRI model simulates increasing P and E. When we examine the field of (P-E), we find that the HadGEM1 trend for the $21^{\text {st }}$ century is weakly decreasing at a rate of $-0.12 \pm 0.28 \mathrm{~kg} \mathrm{~m}^{-2}$ decade $^{-1}$. This rate is not significant at the $90 \%$ confidence level, and the difference plot (Fig. 21) shows spatially the small increases and decreases of (P-E) across the MSRB. Comparing the SM decadal difference plot (Fig. 17) and the (P-E) decadal difference plot (Fig. 21), we see similarities with the increased moisture within the central areas of the MSRB up through the western Great Lakes region, and decreases across the southeastern U.S.

The MRI model simulates increasing $\mathrm{P}$ and $\mathrm{E}$ over the $21^{\text {st }}$ century. The (P-E) trend is upward at $0.06 \pm 0.31 \mathrm{~kg} \mathrm{~m}^{-2}$ decade $^{-1}$, which is also not significant at the $90 \%$ confidence level. This is shown spatially in the Fig. 21 difference plot, where there are large areas of both slightly increasing and slightly decreasing (P-E) values across the MSRB. The drying of the south and southeastern regions of the MSRB and the moistening of the northern plains in the (P-E) decadal difference plot are similar to the areas of drying and moistening shown in the SM decadal difference plot (Fig. 18). 
Evaporation flux last dec. - first dec. $(\mathrm{kg} / \mathrm{m} \wedge 2 / \mathrm{month})$ - Had Gem1 SRES A2

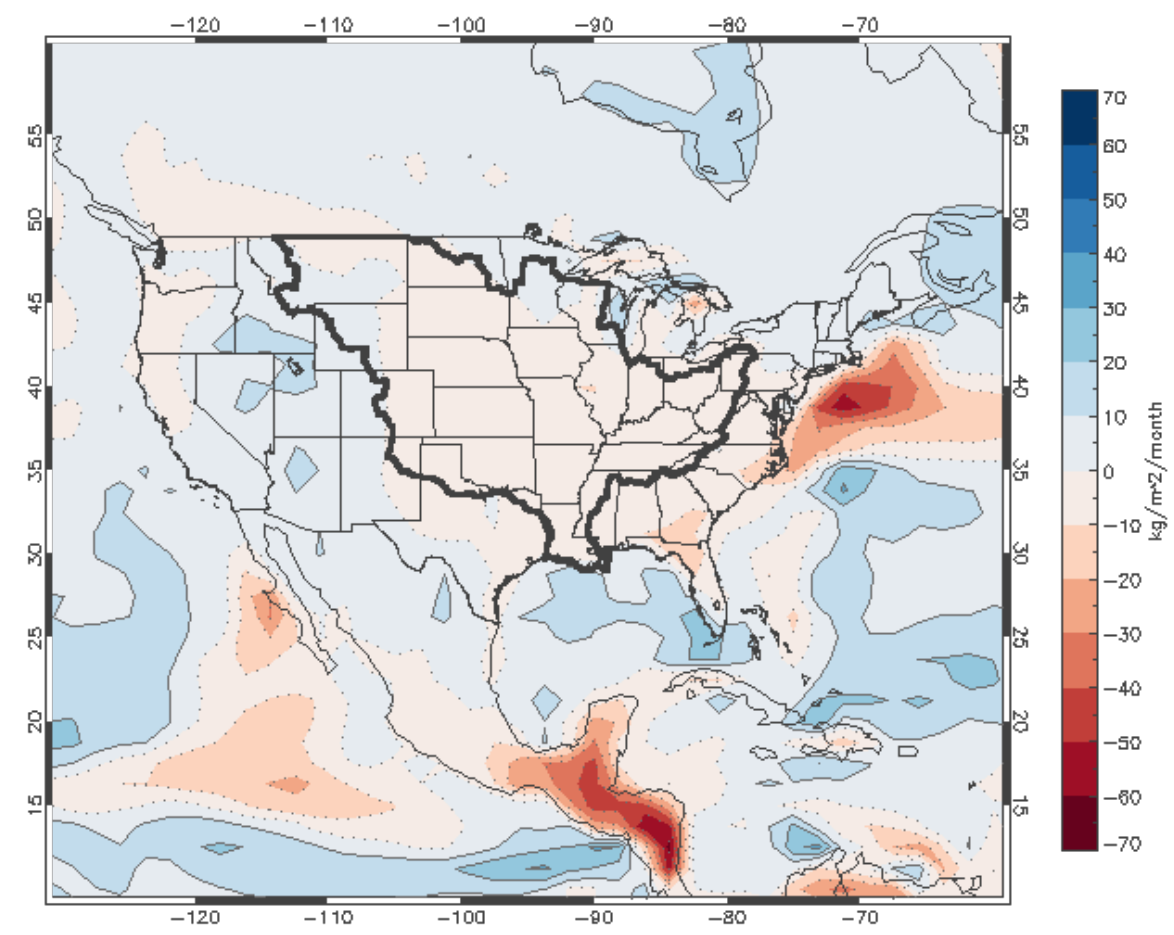

Evaporation flux last dec. - first dec. $(\mathrm{kg} / \mathrm{m} \wedge 2 / \mathrm{month})-$ MRI SRES A2 (run 1)

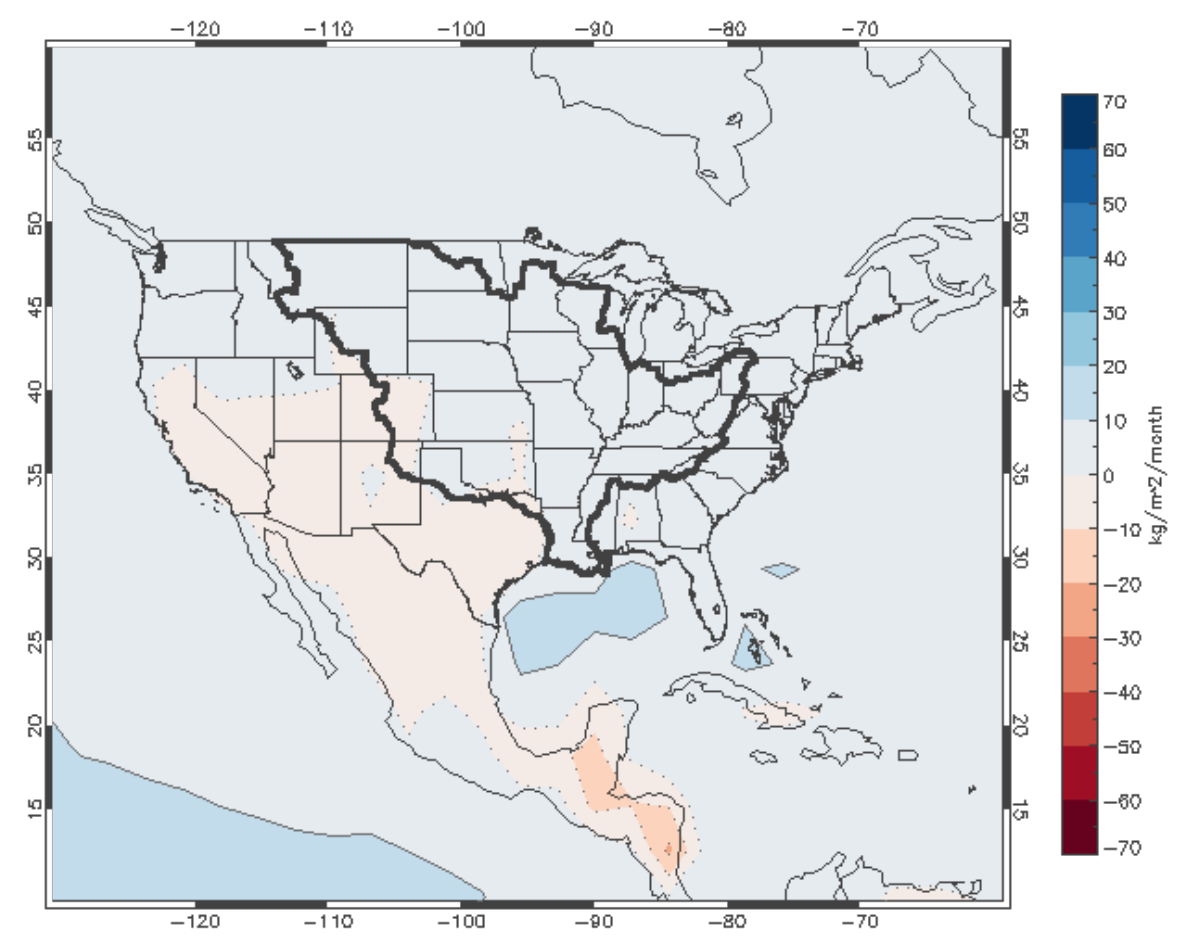

Fig. 20. Difference plot of E for HadGEM1 (top) and MRI (bottom) showing the last decade of the $21^{\text {st }}$ century minus the first decade. Scale is from -70 to $70 \mathrm{~kg} \mathrm{~m}^{-2}$. 


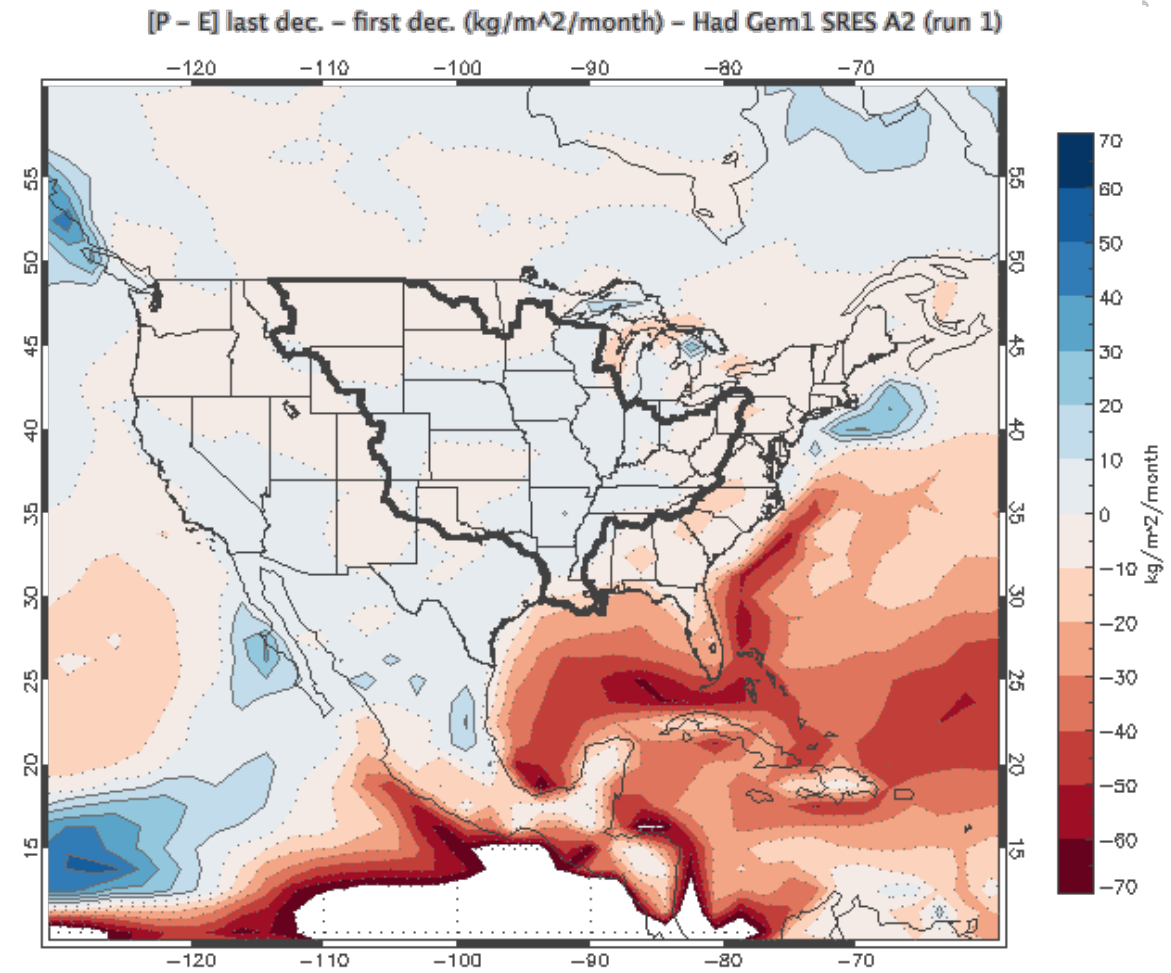

[P - E] last dec. - first dec. ( $\mathrm{kg} / \mathrm{mA} 2 / \mathrm{month})$ - MRI SRES A2 (run 1)

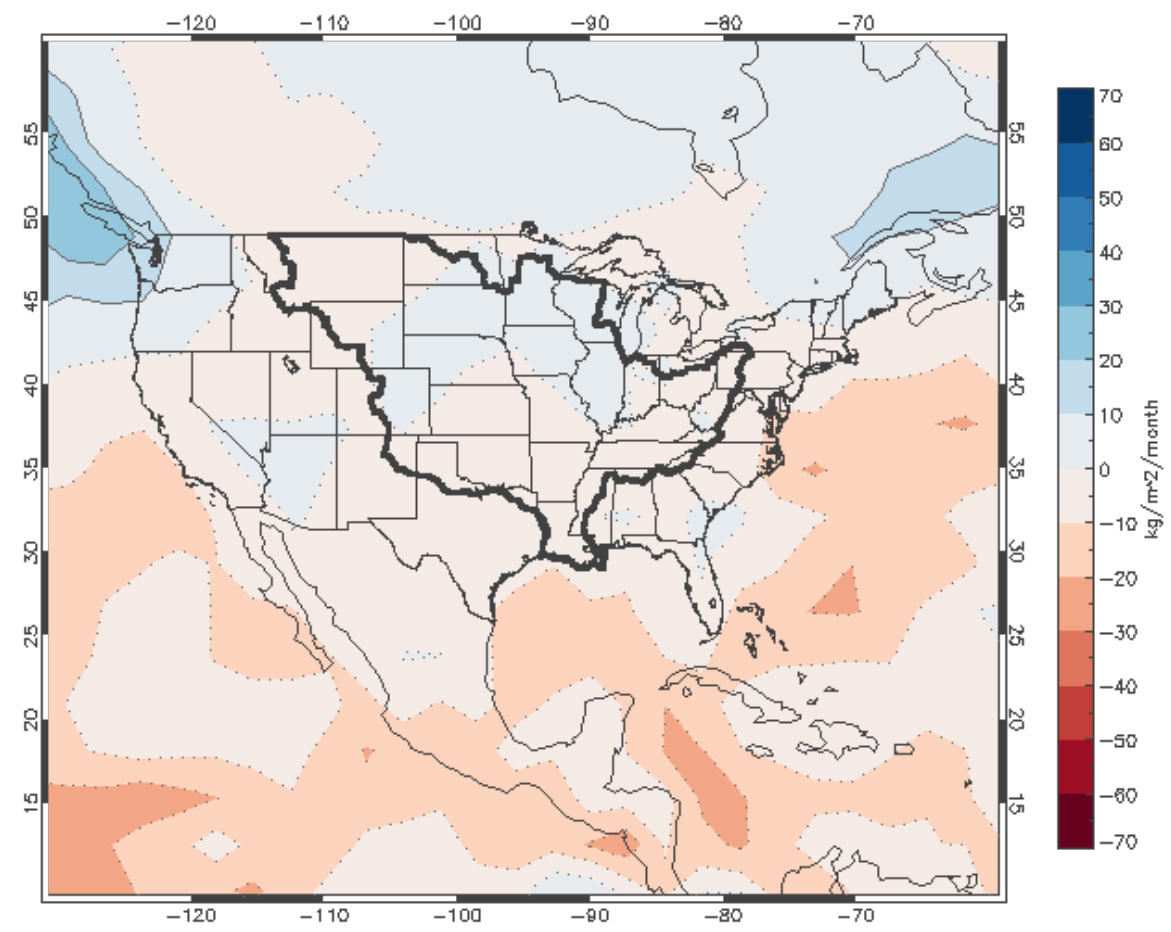

Fig. 21. Difference plot of (P-E) for HadGEM1 (top) and MRI (bottom) showing the last decade of the $21^{\text {st }}$ century minus the first decade. Scale is from -70 to $70 \mathrm{~kg} \mathrm{~m}^{-2}$. 
A summary of the simulated P, E, and (P-E) $21^{\text {st }}$ century A2-projected trends for all models analyzed in this thesis is listed below in Table 9. The models that had significant SM trends (Table 8) are the same models that also have significant (P-E) trends, and show the same increasing/decreasing trend sign. The exception here is the GISS model, which has an increasing (P-E) trend across the MSRB, yet a decreasing SM trend.

Since the distribution and values of SM are approximately given by (P-E), we would expect the plots of each of these to look similar for each model. Spatially, the differences between the first and last decades of the $21^{\text {st }}$ century for both HadGEM1 and MRI show some similarities for areas of moistening and drying when comparing the SM plots to the (P-E) plots. The HadGEM1 SM and (P-E) plots are more similar to each other than the MRI SM and (P-E) plots. This indicates that HadGEM1 may be more realistic in calculating the land parameters of the model.

Table 9. $21^{\text {st }}$ century trends of $\mathrm{P}, \mathrm{E}$, and (P-E) for all models analyzed in this thesis. Trends are in $\mathrm{kg} \mathrm{m}^{-2}$ decade $^{-1}$, and bolded text indicates statistical significance at the $95 \%$ confidence level.

\begin{tabular}{ccccccc}
\hline \hline \multirow{2}{*}{ Model } & \multicolumn{2}{c}{ Precipitation } & \multicolumn{2}{c}{ Evaporation } & \multicolumn{2}{c}{ P - E } \\
\cline { 2 - 7 } & Trend $^{*}$ & Uncert. $^{*}$ & Trend* & Uncert.* & Trend & Uncert.* \\
\hline UKMO HadGEM1 & -0.536 & 0.558 & $\mathbf{- 0 . 4 1 2}$ & $\mathbf{0 . 3 3 0}$ & -0.123 & 0.281 \\
MIROC 3.2 (Med res) & $\mathbf{- 1 . 5 2 0}$ & $\mathbf{0 . 4 0 0}$ & $\mathbf{- 1 . 0 2 3}$ & $\mathbf{0 . 2 8 2}$ & $\mathbf{- 0 . 4 9 7}$ & $\mathbf{0 . 3 2 9}$ \\
UKMO HadCM3 & 0.291 & 0.653 & -0.095 & 0.204 & 0.386 & 0.497 \\
GISS ER & $\mathbf{0 . 8 8 4}$ & $\mathbf{0 . 3 6 2}$ & $\mathbf{0 . 3 6 7}$ & $\mathbf{0 . 1 2 4}$ & $\mathbf{0 . 5 1 7}$ & $\mathbf{0 . 3 8 5}$ \\
MRI-CGCM2.3.2 & $\mathbf{0 . 5 1 0}$ & $\mathbf{0 . 3 8 1}$ & $\mathbf{0 . 4 4 8}$ & $\mathbf{0 . 1 3 7}$ & 0.062 & 0.314 \\
IPSL-CM4 & $\mathbf{- 1 . 1 8 6}$ & $\mathbf{0 . 5 5 1}$ & $\mathbf{- 0 . 4 6 7}$ & $\mathbf{0 . 0 9 9}$ & $\mathbf{- 0 . 7 1 9}$ & $\mathbf{0 . 4 9 2}$ \\
CCSM3 & $\mathbf{1 . 1 6 3}$ & $\mathbf{0 . 4 1 7}$ & $\mathbf{0 . 9 1 7}$ & $\mathbf{0 . 2 9 4}$ & $\mathbf{0 . 2 4 6}$ & $\mathbf{0 . 2 2 9}$ \\
INM-CM3.0 & $\mathbf{- 0 . 7 3 0}$ & $\mathbf{0 . 6 0 5}$ & 0.164 & 0.191 & $\mathbf{- 0 . 8 9 3}$ & $\mathbf{0 . 4 9 0}$ \\
\hline
\end{tabular}

* Trend in $\mathrm{kg} \mathrm{m}^{-2}$ decade $^{-1}$ 
These results draw attention to the fact that different models might give quite different regional results (e.g., quite different patterns of precipitation change over the eastern U.S.), while producing similar area-averaged or even globally-averaged results. This highlights a limitation of IPCC models within the CMIP3 which are developed to give correct global statistics, but which may do less well at predicting correct regional variations. It is possible that the CMIP5 model data, once they become fully available, will be better able to resolve regional climate projections due to the models' generally higher grid resolution when compared to the CMIP3 model data (Stouffer et al. 2011).

\section{Multi-model means}

A multi-model mean annual composite was calculated for the eight models analyzed in this thesis, as Meehl et al. (2007a) have shown that a multi-model ensemble allows the individual model biases to cancel each other out, and the resulting mean shows a more accurately projected climate simulation than any individual model. The dashed blue line in Fig. 22 shows the multi-model mean composite for the eight models analyzed here. The black line is the same GRACE composite shown in Figs. 3 and 4, and the gray shading shows the range of the eight models which were shown individually in Fig. 4. The multi-model composite peaks in April at just below $45 \mathrm{~mm}$, and has a minimum in September at about $-45 \mathrm{~mm}$. The multi-model mean composite compares better overall with the GRACE composite than any of the individual models. After being tested with the same methods as the individual models, we find that the multi-model mean composite correlation to the GRACE composite is 0.993 , the residual area is 39.9 , and the amplitude ratio is 1.06. In comparison to the individual model tests, the best individual correlation 
to GRACE is 0.994 (HadGEM1), the lowest residual area is 75.5 (HadGEM1), and the amplitude ratio closest to 1.0 is 0.88 (IPSL). This shows that, although the individual models vary greatly in their SM annual composite projections, the multi-model ensemble produces results of annual SM change very similar to observations.

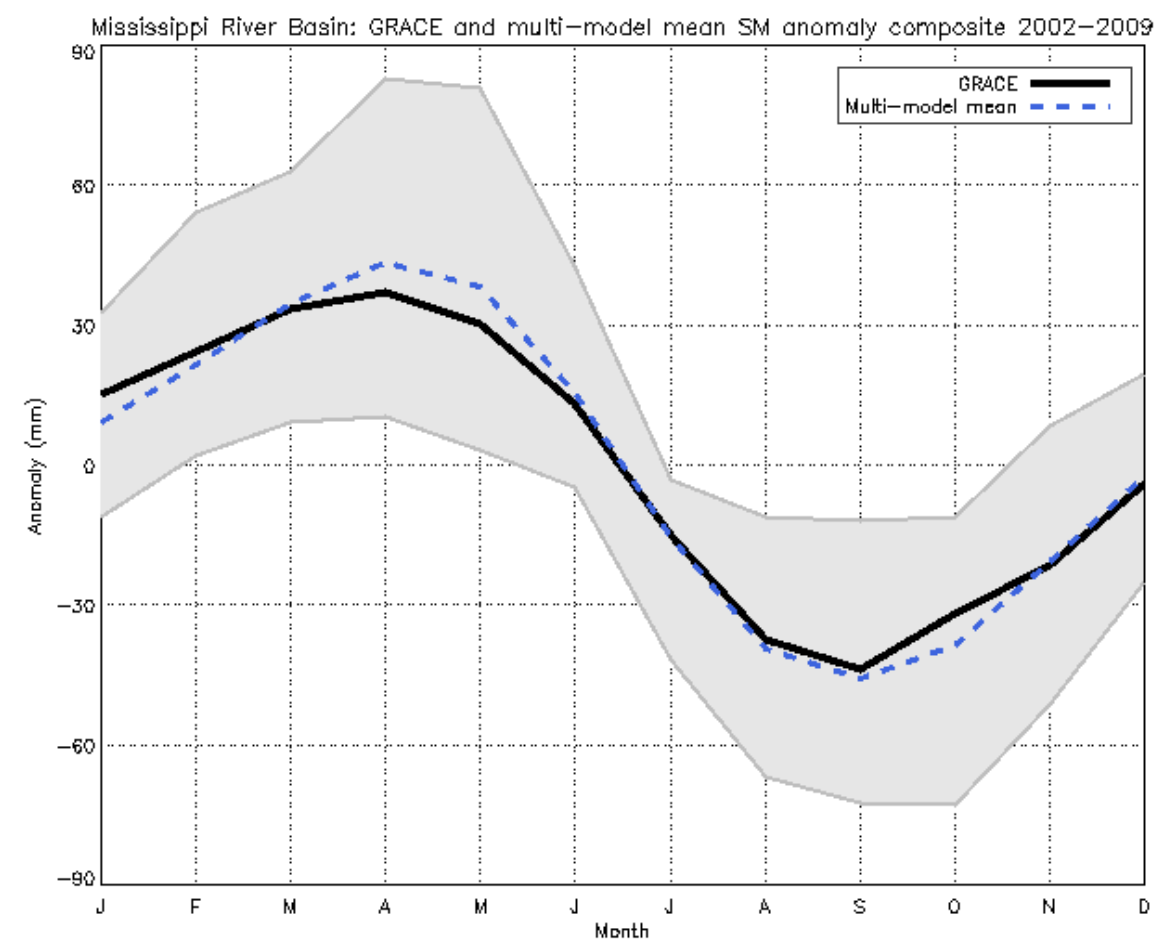

Fig. 22. Multi-model mean annual SM anomaly composite (dashed blue line), versus GRACE composite (solid black line) for the eight models listed in Table 1. Gray shading shows range of SM anomalies projected by individual models. Based on the results shown in Fig. 4.

A multi-model mean $21^{\text {st }}$ century time series trend for SM averaged annually across the MSRB was also calculated. This multi-model mean time series is shown by the black line in Fig 23a, along with the $21^{\text {st }}$ century projections of annually-averaged SM from the eight models analyzed in this thesis. The multi-model mean $21^{\text {st }}$ century trend is 
$-3.78 \pm 1.40 \mathrm{~kg} \mathrm{~m}^{-2}$ decade $^{-1}$, which is significant at the $95 \%$ confidence level and accounts for autocorrelation. This is in contrast to the positive HadGEM1 trend (3.74 \pm $3.34 \mathrm{~kg} \mathrm{~m}^{-2}$ decade $\left.^{-1}\right)$. The multi-model mean, however, may be influenced by the unrealistically high MIROC SM, which starts at about $1200 \mathrm{~kg} \mathrm{~m}^{-2}$, almost twice the value of most of the other models, and then decreases at a higher rate of change $(-31.3 \mathrm{~kg}$ $\mathrm{m}^{-2}$ decade $^{-1}$ ) than the other models to around $900 \mathrm{~kg} \mathrm{~m}^{-2}$ by the end of the century. The majority of the models project SM to be between about 600 to $800 \mathrm{~kg} \mathrm{~m}^{-2}$ throughout the $21^{\text {st }}$ century, consistent with NARR climatological SM values. The IPSL model, however, projects SM to be unrealistically low at below $300 \mathrm{~kg} \mathrm{~m}^{-2}$ for the $21^{\text {st }}$ century. A new multi-model mean SM time series was then created after discarding the obvious outliers - IPSL and MIROC. A new multi-model mean annual SM anomaly composite was also created for these six models (not shown) and looks almost identical to the multi-model mean in Fig. 22. The six "good" model time series for the $21^{\text {st }}$ century are shown in Fig. 23b, with the new "good" multi-model mean time series overlaid in black. The "good" multi-model $21^{\text {st }}$ century time series trend is $0.739 \pm 1.33 \mathrm{~kg} \mathrm{~m}^{-2}$ decade $^{-1}$, and is not significant at the $95 \%$ or $90 \%$ confidence levels. 


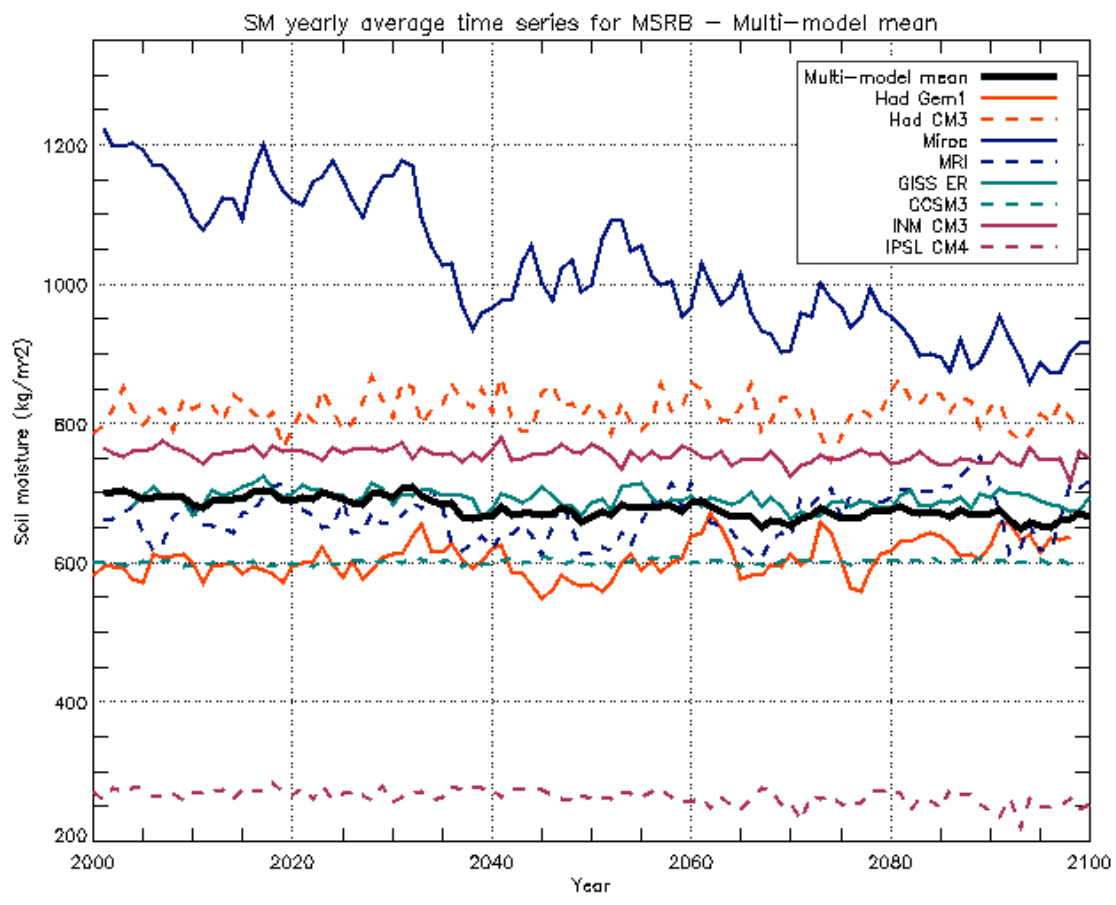

a)

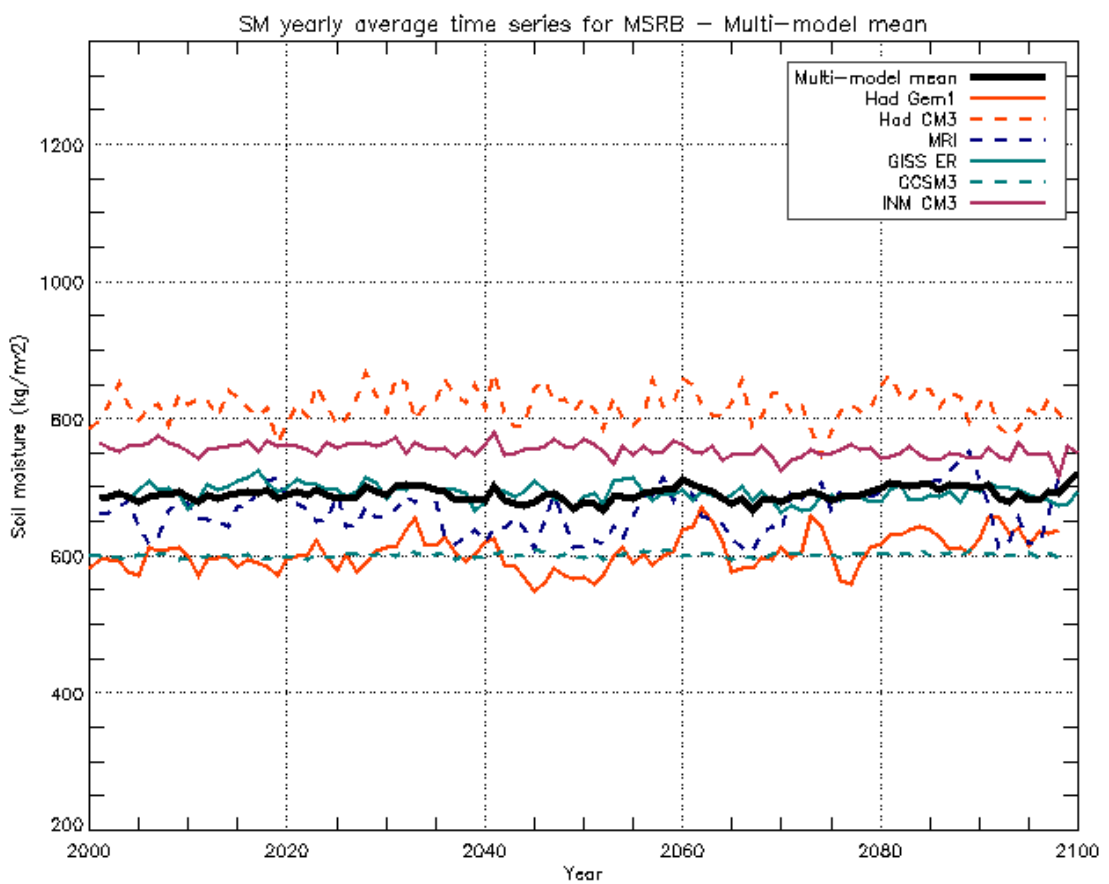

b)

Fig. 23. Top (a): $21^{\text {st }}$ century time series of annually-averaged SM for all eight models analyzed with multi-model mean. Bottom (b): $21^{\text {st }}$ century time series with multi-model mean of annually-averaged SM for six models, excluding IPSL and MIROC from the original eight. 
The multi-model mean annual SM anomaly composite comparison to the GRACE composite shows that the models on average reasonably simulate the annual SM change within the MSRB. However, we argue that many models, especially MIROC and IPSL, should be eliminated from the $21^{\text {st }}$ century SM trend analysis when considering that the absolute values of SM as displayed in the spatial distribution plots vary greatly and that most do not compare well to NARR.

\section{Summary and discussion}

In this thesis, our goal was to examine soil moisture (SM) trends in the

Mississippi River Basin (MSRB) as simulated by select IPCC models over the $21^{\text {st }}$ century. We did this by first looking at GRACE observational data of total water storage (TWS) anomalies in the MSRB for the time period May 2002 through November 2009. The annual composite for this basin-averaged data was used to compare to the soil moisture content data from select IPCC models run under the A2 scenario. This comparison determined which models are valid to use for analyzing water storage trends within the MSRB.

To determine which of these select IPCC models best represent observed SM in the MSRB, the GRACE annual composite was compared to each model's annual composite through correlation tests and analysis of the amplitude differences. All modelsimulated SM annual cycles show good correlations with GRACE data when composited for the MSRB. However, there are considerable differences in amplitude (Fig. 4). The amplitude ratios between the models and GRACE show that the annual model-simulated 
SM change was anywhere from $37 \%$ to $175 \%$ of the observed SM change (Table 4). These comparisons to GRACE show that the seasonal timing of model-simulated SM change is accurate in most cases, which is also supported by a multi-model mean annual SM anomaly composite, which performs better when compared to the GRACE composite than any of the individual models. However, the actual amount of yearly SM change projected in some models is much different than observed changes.

Our comparisons of model output with GRACE data suggest that the HadGEM1 and MRI models are the most accurate in simulating average SM over the MSRB for the GRACE observational period. This conclusion is based on only the eight years of GRACE data; analysis over a longer period might be more or less convincing, but the data are not available through the University of Colorado GRACE online database (University of Colorado 2010), which was primarily used due to the availability of processed GRACE data averaged over river basins. It is also possible that the two models we identified may simulate SM well for the MSRB, but not over other river basins around the globe.

Both HadGEM1 and MRI models show a weak upward trend in SM within the MSRB during the $21^{\text {st }}$ century, but neither result is significant at the $95 \%$ confidence level. There is also regional variability in the trends, both upward and downward, in all the models analyzed. Although the HadGEM1 and MRI models both have upward SM trends, they have opposing trends for precipitation (P), evaporation (E), and their difference (P-E). One common spatial feature between these top two models is drying 
along the southeast region of the Atlantic coast. This is seen in both the SM (Figs. 17 and 18) and (P-E) decadal difference plots (Fig. 21) for HadGEM1 and MRI.

The actual SM spatial distributions within the MSRB are highly variable between each IPCC model analyzed in this thesis. This is likely due to the different parameterizations used in the models for the calculation of evaporative fluxes between atmosphere and land, and combined surface and groundwater runoff (R). Our analysis of basin-averaged values for SM, P, E, and R over the GRACE observational period suggests that $\mathrm{R}$ is the driving removal term in the moisture balance determining $\mathrm{SM}$ values within the land models. With average P (i.e., water input to the land) being roughly the same for most models, high R (i.e., water leaving the land) leads to low SM, which means there is less moisture available for $\mathrm{E}$, and vice versa. This suggests that more work needs to be done to accurately simulate SM consistently across the IPCC suite by first simulating R more accurately.

Based on the comparison tests with the GRACE data, and the highly variable simulated SM distributions across the IPCC suite, we conclude that water storage data as presented by the majority of the IPCC models from the CMIP3 dataset are not yet reliable for simulating changes over the $21^{\text {st }}$ century. However, the HadGEM1 model seems to simulate SM in the MSRB reasonably well, and projects an upward trend in SM of $3.74 \pm$ $3.34 \mathrm{~kg} \mathrm{~m}^{-2}$ decade $^{-1}$, which is confident at the $90 \%$ confidence level.

An analysis similar to the one presented in this thesis could be performed using model simulations with scenarios other than A2. Since current global emissions are exceeding the amounts described under the A2 scenario (Allison et al. 2009; Betts et al. 
2009; Raupach and Fraser 2011), perhaps a scenario with greater emissions would be more realistic. Also, with the CMIP5 data soon to be released, this analysis should be repeated with the newest IPCC model output to determine if any significant improvements have been made for the land models within these GCM's.

It would also be ideal to perform a similar analysis as the one presented in this thesis with smaller river basins, such as the San Joaquin and Sacramento River basins within California, a state that has a large agricultural industry. However, for this type of analysis, the size of the study area would restricted by the GRACE resolution, and downscaled climate data would need to be used, as the CMIP3 IPCC models' grid resolutions are too coarse to do an accurate averaging for these smaller river basins. In this case, the CMIP5 datasets might be more useful, as those models' resolutions are generally higher than the CMIP3 models' resolutions (Stouffer et al. 2011). 


\section{REFERENCES}

Allison, I., and Coauthors, 2009: The Copenhagen Diagnosis: Updating the World on the Latest Climate Science, SOS Print + Media, 60 pp.

Anderson, D. M., and Coauthors, 2009: Global Climate Change Impacts in the United States, T. R. Karl, J. M. Melillo, and T. C. Peterson, Eds., Cambridge University Press, $196 \mathrm{pp}$.

Anderson, O. B., S. I. Seneviratne, J. Hinderer, and P. Viterbo, 2005: GRACE-derived terrestrial water storage depletion associated with the 2003 European heat wave. Geophys. Res. Lett., 32, L18405, doi:10.1029/2005GL023574.

Betts, R. A., M. Collins, D. L. Hemming, C. D. Jones, J. A. Lowe, and M. Sanderson, 2009: When could global warming reach $4^{\circ} \mathrm{C}$ ?. Hadley Centre Tech. Note 80, 23 pp.

Cox, P.M., R.A. Betts, C.B. Bunton, R.L.H. Essery, P.R. Rowntree, and J. Smith, 1999: The impact of new land surface physics on the GCM simulation of climate and climate sensitivity. Climate Dyn., 15, 183-203.

CSR (Center for Space Research), cited 2012: GRACE Mission Data Flow. [Available online at http://www.csr.utexas.edu/grace/asdp.html.]

Dai, Y. and Coauthors, 2003: The Common Land Model. Bull. Amer. Meteor. Soc., 84, 1013-1023, doi:10.1175/BAMS-84-8-1013.

GSFC (Goddard Space Flight Center), 2003: Studying the Earth's Gravity from Space: The Gravity Recovery and Climate Experiment (GRACE). NASA Facts FS-20021-029-GSFC, 6 pp.

Ho, S. L., 2009: Total water storage change over the San Joaquin and Sacramento river basins - Comparing GRACE and observational data. Senior thesis, Dept. of Earth System Science, University of California, Irvine, $16 \mathrm{pp}$.

JPL (Jet Propulsion Laboratory), cited 2011a: GRACE. [Available online at http://podaac.jpl.nasa.gov/gravity/grace.]

JPL (Jet Propulsion Laboratory), cited 2011b: GRACE 'months'. [Available online at http://gracetellus.jpl.nasa.gov/data/GraceMonths/.] 
Meehl, G. A., and Coauthors, 2007a: Global climate projections. Climate Change 2007: The Physical Science Basis, S. Solomon et al., Eds., Cambridge University Press, 747-845.

Meehl, G., and Coauthers, 2007b: IPCC Standard Output from Coupled OceanAtmosphere GCMs. [Available online at http://wwwpcmdi.llnl.gov/ipcc/standard_output.html.]

Music, B., and D. Caya, 2007: Evaluation of the Hydrological Cycle over the Mississippi River Basin as Simulated by the Canadian Regional Climate Model (CRCM). J. Hydrometeor., 8, 969-988.

Nakicenovic, N. and Coauthors, 2000: Emissions Scenarios, N. Nakicenovic and R. Swart, Eds., Cambridge University Press, 570 pp.

NOAA ESRL PSD (National Oceanic \& Atmospheric Administration / Earth System Research Laboratory / Physical Sciences Division), cited 2011: NCEP North American Regional Reanalysis: NARR. [Available online at http://www.esrl.noaa.gov/psd/data/gridded/data.narr.subsurface.html.]

NPS (National Park Service), cited 2011: Mississippi River Facts. [Available online at http://www.nps.gov/miss/riverfacts.htm.]

NCL (NCAR Command Language), cited 2010: Shapefiles. [Available online at http://www.ncl.ucar.edu/Applications/shapefiles.shtm.]

PCMDI (Program for Climate Model Diagnosis and Intercomparison), cited 2010: About the WCRP CMIP3 Multi-Model Dataset Archive at PCMDI. [Available online at http://www-pcmdi.llnl.gov/ipcc/about_ipcc.php.]

Ramillien, G., J. S. Famiglietti, and J. Wahr, 2008: Detection of Continental Hydrology and Glaciology Signals from GRACE: A Review. Surveys in Geophysics, 29, 361-374, doi:10.1007/s10712-008-9048-9.

Randall, D. A., and Coauthors, 2007: Climate models and their evaluation. Climate Change 2007: The Physical Science Basis, S. Solomon et al., Eds., Cambridge University Press, 589-662.

Raupach, M., and P. Fraser, 2011: Climate and greenhouse gases. Climate Change: Science and Solutions for Australia, H. Cleugh, M. S. Smith, M.Battaglia, and P. Graham, Eds., CSIRO, 15-34. 
Robock, A., K.Y. Vinnikov, G. Srinivasan, J.K. Entin, S.E. Hollinger, N.A. Speranskaya, S. Liu, and A. Namkhai, 2000: The Global Soil Moisture Data Bank. Bull. Amer. Meteor. Soc., 81(6), 1281-1299.

Rodell, M., and J. S. Famiglietti, 2001: An analysis of terrestrial water storage variations in Illinois with implications for the Gravity Recovery and Climate Experiment (GRACE). Water Resour. Res., 37(5), 1327-1339.

Rodell, M., and J. S. Famiglietti, 2002: The potential for satellite-based monitoring of groundwater storage changes using GRACE: the High Plains aquifer, Central US. J. Hydrol., 263, 245-256.

Rodell, M., J. Chen, H. Kato, J. S. Famiglietti, J. Nigro, and C. R. Wilson, 2007: Estimating groundwater storage changes in the Mississippi River basin (USA) using GRACE. Hydrogeol. J., 15(1), 159-166, doi:10.1007/s10040-006-0103-7.

Rodell, M., 2008: Remote sensing of terrestrial water storage and application to drought monitoring. Extended Abstracts, Contributions of Satellite Remote Sensing to Drought Monitoring, Boulder, CO, National Integrated Drought Information System. [Available online at http://www.drought.gov/imageserver/NIDIS/ workshops/remotesensing/abstracts/matt_rodell.pdf.]

Seneviratne, S. I., T. Corti, E. L. Davin, M. Hirschi, E. B. Jaeger, I. Lehner, B. Orlowsky, and A. J. Teuling, 2010: Investigating soil moisture-climate interactions in a changing climate: A review. Earth-Sci. Rev., 99, 125-161.

Solomon, S., D. Qin, M. Manning, Z. Chen, M. Marquis, K.B. Averyt, M. Tignor, and H.L. Miller, Eds., 2007: Climate Change 2007: The Physical Science Basis. Cambridge University Press, 996 pp.

Stouffer, R. J., K. E. Taylor, and G. A. Meehl, 2011: CMIP5 Long-term experimental Design. CLIVAR Exchanges, No. 56, 16(2), 5-7.

Swenson, S., and J. Wahr, 2009: Monitoring the water balance of Lake Victoria, East Africa, from space. J. Hydrol., 379, 163-176.

University of Colorado, cited 2010: University of Colorado Real-Time GRACE Data Analysis Site. [Available online at http://geoid.colorado.edu/grace.]

Wahr, J., S. Swenson, V. Zlotnicki, and I. Velicogna, 2004: Time-variable gravity from GRACE: First results. Geophys. Res. Lett., 31, L11501, 4 pp., doi:10.1029/2004GL019779. 
Wigley, T. M. L., 2006: Statistical Issues Regarding Trends. Temperature Trends in the Lower Atmosphere: Steps for Understanding and Reconciling Differences, T. R. Karl, S. J. Hassol, C. D. Miller, and W. L. Murray, Eds., A Report by the U.S. Climate Change Science Program and the Subcommittee on Global Change Research, Washington, DC, 129-139. 